\title{
INL Experimental Roadmap for Thermal Hydraulic Code Validation
}

\author{
Glenn E. McCreery \\ Hugh M. Mcllroy
}

September 2007

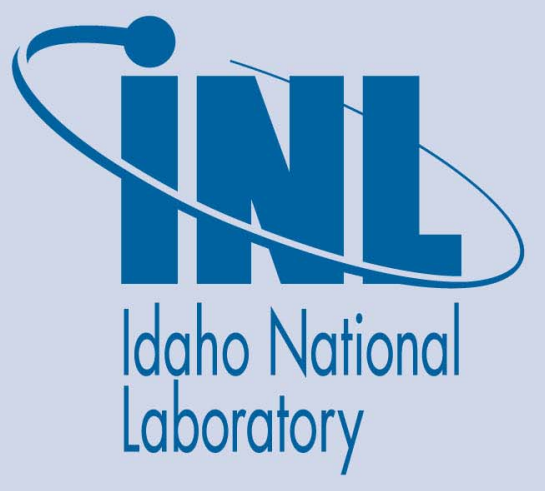

The INL is a U.S. Department of Energy National Laboratory operated by Battelle Energy Alliance 
INL/EXT-07-13248

\title{
INL Experimental Roadmap for Thermal Hydraulic Code Validation
}

\author{
Glenn E. McCreery \\ Hugh M. Mcllroy
}

September 2007

\begin{abstract}
Idaho National Laboratory
Idaho Falls, Idaho 83415
\end{abstract}

Prepared for the

U.S. Department of Energy

Through the INL LDRD Program

Under DOE Idaho Operations Office

Contract DE-AC07-05ID14517 
INL/EXT-07-13248

\title{
INL Experimental Program Roadmap for Thermal Hydraulic Code Validation
}

\author{
Glenn McCreery and Hugh McIlroy
}

\section{Table of contents}

Summary

I. Introduction

II. Validation Experiments Requirements

III. INL Thermal Hydraulics Capabilities

III.1. Historical Capabilities

III.2. Present Capabilities

III.3. Present INL-University Collaborative Thermal Hydraulic Research

IV. Path Forward

IV.1. VHTR Thermal Hydraulic Research

IV.1.1. Upper And Lower Plenum Experiments

IV.1.2. Air-Ingress Experiments

IV.1.3. Core Heat Transfer And Turbulence Experiments 20

IV.1.4. Electrically-Heated Integral VHTR Facility 21

IV.2. Sodium-Cooled Fast Reactor Thermal Hydraulic Experiment Program

IV.2.1. Matched Index-Of-Refraction Rod Bundle Experiment 22

IV.2.2. Sodium-Cooled Rod Bundle Heat Transfer Facility 22

IV.2.3. Restart Of Existing Nak Flow Loop 27

IV.2.4. Sodium Pool Natural Circulation Facility 27

IV.2.5. Instrumentation Development 28

IV.3. Light Water Reactor Research $\quad 30$

IV.3.1. Light Water Reactor Phenomena $\quad 30$

IV.3.2. Electrically-Heated Integral Facility 32

$\begin{array}{ll}\text { IV.3.4 ATR Flow Loop } & 32\end{array}$

IV.3.5. Reactivity feedback thermal hydraulic experiment 32

Appendix 1. Fast Reactor Rod Bundle Matched Index-Of-Refraction

Experiments

35

A1.1. Matched Index-Of-Refraction (MIR) Facility 35

A1.2. Particle Image Velocimetry (PIV) System 36

A1.3. Preliminary Matched Index-Of-Refraction Rod Bundle

Experiment Design

Appendix 2. Sodium Cooled Rod Bundle Facility Preliminary Cost

$$
\text { Estimate }
$$

Appendix 3. Laboratory Candidate Buildings $\quad 54$

A3.1. In-Town Facilities $\quad 54$

A3.2. MFC Facilities Suitable For Sodium Handling 56

A3.3. Possible Integral Reactor Simulation Facilities 58

Appendix 4. Scaling Approaches For Light-Water Reactor

Electrically-Heated Integral Facilities 


\section{Summary}

Advanced computer modeling and simulation tools and protocols will be heavily relied on for a wide variety of system studies, engineering design activities, and other aspects of the Next Generation Nuclear Power (NGNP) Very High Temperature Reactor (VHTR), the DOE Global Nuclear Energy Partnership (GNEP), and light-water reactors. The goal is for all modeling and simulation tools to be demonstrated accurate and reliable through a formal Verification and Validation $(\mathrm{V} \& \mathrm{~V})$ process, especially where such tools are to be used to establish safety margins and support regulatory compliance, or to design a system in a manner that reduces the role of expensive mockups and prototypes. Recent literature identifies specific experimental principles that must be followed in order to insure that experimental data meet the standards required for a "benchmark" database. Even for well conducted experiments, missing experimental details, such as geometrical definition, data reduction procedures, and manufacturing tolerances have led to poor Benchmark calculations.

The INL has a long and deep history of performing research in thermal hydraulics, especially in the 1960s through 1980s when many programs such as LOFT and Semiscle were devoted to light-water reactor safety research, the EBRII fast reactor was in operation, and a strong geothermal energy program was established. The past can serve as a partial guide for reinvigorating thermal hydraulic research at the laboratory. However, new research programs need to fully incorporate modern experimental methods such as measurement techniques using the latest instrumentation, computerized data reduction, and scaling methodology. The path forward for establishing experimental research for code model validation will require benchmark experiments conducted in suitable facilities located at the INL. This document describes thermal hydraulic facility requirements and candidate buildings and presents examples of suitable validation experiments related to VHTRs, sodium-cooled fast reactors, and light-water reactors. These experiments range from relatively low-cost benchtop experiments for investigating individual phenomena to large electrically-heated integral facilities for investigating reactor accidents and transients. 


\section{Introduction}

The strategic vision of the Idaho National Laboratory (INL) is to be the "preeminent nuclear laboratory with synergistic, world-class, multi-program capabilities and partnerships" within ten years. To achieve this leadership role the INL has established strategic objectives to lead the development of advanced nuclear systems. The strategic objectives include, among others, the development of better modeling and simulation capabilities to support more efficient design and licensing processes and the advancement of basic process theory and the design of complex energy systems using advanced numerical modeling and computer simulations based at the Center for Advanced Modeling and Simulation (CAMS). Accomplishment of these objectives requires worldclass modeling and simulation capability and world-class experimental capabilities to validate the modeling and simulation results. The goals are to make the INL the leader in reactor CFD validation, with an initial concentration on fast reactor and high-temperature gas reactor (HTGR) core thermal hydraulics and to later develop CFD validation capabilities for other components and for light-water reactors. The goals will require both separate effects and integral experiments.

Advanced computer modeling and simulation tools and protocols will be heavily relied on for a wide variety of system studies, engineering design activities, and other aspects of the Next Generation Nuclear Power (NGNP) Very High Temperature Reactor (VHTR) and the rapidly coalescing DOE Global Nuclear Energy Partnership (GNEP). All NGNP and GNEP modeling and simulation tools must be demonstrated to be accurate and reliable through a formal Verification and Validation $(\mathrm{V} \& \mathrm{~V})$ process, especially where such tools are to be used to establish safety margins and support regulatory compliance, or to design a system in a manner that reduces the role of expensive mockups and prototypes (The actual $V \& V$ processes and data sets used for validation of systems codes such as RELAP5 and more mechanistic CFD codes will necessarily differ).

Thermal-hydraulic phenomena that are exhibited in nuclear reactors may be classified as 1) integral phenomena, that is the coupled response of the whole reactor during normal, transient or accident conditions, 2) phenomena occurring within a particular component, for example flow distribution within a plenum, and 3) phenomena occurring on the subcomponent level, for example heat transfer on a surface or turbulence within an eddy. Experiments that model integral effects are typically carried out in large integral facilities, such as Semiscale (Loomis, 1987) and LOFT (Nalezny, 1983), that model the complete reactor primary system plus connected heat transfer and safety systems. Experiments that model phenomena in a component are often geometrically scaled to the prototype component and simulate the often three-dimensional "separate effects" within the component. Basic phenomena that are exhibited on the sub-component level require fine-resolution measurements to resolve, for example laser anemometry measurements of velocity and turbulence parameters within a small measurement volume. Data generated at the integral, component and sub-component levels are all required for code validation. 
Code validation experiments are typically carried out in scaled model facilities. For large prototype components the representative volume of the model is usually smaller than the prototype (but not always; the matched index-of-refraction experiment, proposed in the path forward section, employs larger than prototype diameter representation of fuel rods in order to insure sufficiently high Reynolds numbers for fully turbulent flow and fine velocity measurement resolution). Reduced model size is important where the complete reactor, including safety and heat removal systems, is modeled as an integral system and where maximum size is dictated by practical considerations such as electrical power and building size as well as by scaling relationships. The processes modeled in the facility must exhibit both qualitative similarity, i.e. the physical phenomena exhibited in the model is the same as in the prototype and reasonable, if not exact, quantitative similarity of the scaled dependant variables of the process. Similarity is more easily achieved in a steady flow and heat transfer process than in a dynamic process, such as a blowdown following a Loss of Coolant Accident (LOCA). Geometric similarity of model and prototype is often employed where three-dimensional velocity profiles are to be simulated, such as in a model of natural circulation in a pool of a fast reactor or the lower plenum flow of a VHTR (McCreery, et al., 2007). Geometric similarity has been less often employed in light-water reactor integral experiments where it is often more important to preserve pressure, including hydrostatic pressure, for component flows that are essentially one-dimensional. This approach produces the "full-height full-pressure" scaling methodology (Condie et al., 1987) employed in the Semiscale, Westinghouse FLECHT, ROSA-IV, etc. integral facilities. More recently, scaling approaches that use a reduced-height (shorter and fatter) facility have been employed, e.g., the PUMA facility at Purdue University (Ransom et al., 1998), and the APEX facility at Oregon State University (Reyes and Hochreiter, 1998).

Transient two-phase flow is important in a variety of fast and light-water reactor thermalhydraulics problems. Validation of mechanistic models for the interfacial transport of mass, heat and momentum requires measurements that are both localized and transient. Good mechanistic models of flow regimes are still not available for complex geometries, developing flows, and transient situations.

This document presents a brief overview of code validation requirements. This is followed by a description of historical and present thermal hydraulic capabilities at the INL. The path forward to establish experimental research for code model validation will require benchmark experiments conducted in suitable facilities located at the INL. Facility requirements and candidate buildings are described. This is followed by descriptions of suitable validation experiments related to (1) VHTRs, (2), sodium-cooled fast reactors, and (3), light-water reactors. 


\section{Validation Experiments Requirements}

A review of the technical literature reveals a huge number of reports that document the results of various experimental studies. However, few of these reports describe in sufficient detail the critical elements of the experiment such as initial or boundary conditions or uncertainty (error) estimates and analysis that are necessary for consideration as a source of data for CFD code validation. Additionally, the literature indicates that there is a need to identify specific experimental principles that must be followed in order to ensure that experimental data meet the standard required of a "benchmark" database.

Roach (1998) summarizes a review by Barber (1998) that details examples where missing experimental details lead to poor Benchmark calculations and the importance of geometrical definition, data reduction procedures and the dominant physics. Barber stresses that the geometrical definition of a model must include an accurate reproduction of the fabrication tolerances of the actual geometry and that the geometric definition must account for changes that may occur in the actual geometry at operating conditions (temperature-related expansion, etc.). Barber also establishes that the data reduction technique used for both the code and experimental data should be the same and that the dominant physics must be understood and verified because physically inconsistent but mathematically correct possible solutions can be predicted by CFD codes. Roach also includes points from a paper by Marvin (1995) that describe the efforts at NASA to develop a comprehensive approach to CFD validation. Marvin stresses the building block, benchmark and design experiment approach for obtaining measurements needed for validation and measurement accuracy.

The advances made by NASA (and others) are highly relevant to the discussion of experiments for CFD code validation because of their extensive code validation efforts relating to the Space Shuttle program and support of the Boeing 777 aircraft design and development. The experience of NASA indicates that several principles (or perhaps rules or guidelines) can be identified:

- The aerodynamic community may have the best approach and most relevant experience in developing experimental programs for code validation;

- A team approach that merges CFD and experimental expertise should be used to ensure an integrated and standardized approach to data and code results analysis;

- Geometric definition, data reduction techniques and the dominant physics must be understood and employed by the experimental and CFD team.

Additional experimental facilities and validation programs that should be reviewed (and possibly visited) include:

- NASA Langley Research Center; 
- NASA Ames Research Center;

- Sandia National Laboratory (e.g., Marty Pilche)

- MIT

- Boeing

- Stanford;

- Purdue.

Conferences and proceedings of the International Gas Turbine Institute (IGTI) (several sessions devoted to aircraft engine modeling and simulation, experimental methods [heat transfer, film cooling, etc.], experimental and numerical life assessments of structures, test facilities and integrated design methodologies, design analysis and validation, computational/design/experimental studies in aerodynamics and heat transfer, CFD methods at the TurboExpo 2007 see http://www.asmeconferences.org/te07/

\section{INL Thermal hydraulics Capabilities}

Thermal hydraulics capabilities at the INL are presented from both a historical and present day perspective. Because the INL has lost much of its thermal hydraulic experimental capability compared to, especially, the 1970s when many programs such as LOFT and Semiscle were devoted to light-water reactor safety research, the EBRII fast reactor was in operation, and a strong geothermal program was established. The past can serve as a partial guide for reinvigorating thermal hydraulic research. However, the path forward needs to fully incorporate modern experimental methods equipment such as instrumentation, computerized data reduction, and scaling methodology rather than recreating what was in hind-sight rather crude approaches.

\section{III.1. Historical Capabilities}

The INL has a long history of conducting thermal hydraulics experiments related to nuclear power and, primarily, to light water reactor safety. The Loss of Fluid Test (LOFT) (Nalezny, 1983) was originally conceived in 1964 to "load up a reactor and the containment building with instrumentation, operate the reactor, and then withhold the coolant to see what happens" (Stacy, 2000). This was probably not a good design approach from a code validation standpoint. After years of more careful consideration and development of the electrically-heated Semiscale reactor simulator (Loomis, 1987) beginning in the late 1960s, the emphasis for LOFT was shifted to the investigation of loss-of-coolant accidents (LOCAs) and emergency core coolant system performance. Concurrently, computer models that predicted the fluid behavior of LOCAs, such as RELAP, were developed at the site. Experiments performed in the LOFT and Semiscale facilities were directed at validating the accuracy of these computer programs. The emphasis on early LOFT and Semiscale experiments was what was then considered to be the worst case scenario; a double-offset shear of a primary coolant pipe. The occurrence of the Three Mile Island reactor accident in 1979 immediately changed the direction of 
both programs to the investigation of small-break and mid-size break accidents with complications such as loss of off-site power. Compared with other thermal hydraulic reactor safety experiments of their era (some of which are proprietary), data from the Semiscale and LOFT experiments are well documented, including system dimensions and instrument and data uncertainties. Data from these experiments are being used to this day for code validation purposes.

The Semiscale system was housed in the Water Reactor Research Test Facility (WRRTF) which was also used for a variety of component and instrumentation test for Semiscale and LOFT as well as separate effects experiments, such as the auxiliary-feedwater experiment shown in Figure 1 (McCreery, et al., 1989), and experiments that used the Steam-Air-Water two-phase flow loop shown in Figure 2. WRRTF was a large high-bay facility equipped with an overhead crane, the several megawatts of electrical power required for Semiscale, and sufficient interior height (including a floor pit) for the approximately $20 \mathrm{~m}$ height of the Semiscale facility. An advisory committee consisting of Franz Durst of the University of Erlangen, Robert Moffat of Stanford University and Ray Viskanta of Purdue University was assembled in 1992 to assess the long term research capabilities of the INL in experimental thermosciences (Durst et al., 1992). The report stated that "WRRTF is an impressive laboratory with large scale infrastructure which is well suited to be competitive with large-scale research projects being conducted in the world. The Advisory Committee felt that this facility should be kept on-line and factored into future plans as a host facility. ..." . Unfortunately, WRRTF, which suffered from a lack of maintenance and funded projects in the 1990s, was demolished as part of the INL footprint reduction program.

The May Street North Thermal Science Laboratory was established in 1990 to provide an in-town alternative to WRRTF for conducting small-scale experiments. A large variety of fluid mechanics experiments, both single-phase and two-phase, and heat transfer experiments were conducted in the laboratory until it was relocated to its present location at Bonneville County Technology Center (BCTC) Bay 9.

Experimental Breeder Reactor II (EBRII) was constructed in 1961 and operated until 1994. Although it's primary purposes were to demonstrate on-site fuel reprocessing, to provide on-site electrical power, and for fuel and structural sample irradiation (Stacy, 1999), EBR-II conducted safety tests starting in the mid-1970s that are of use for thermal hydraulic code validation. Tests included 1) overpower transients, 2) undercooling transients, and 3) natural circulation transients. Major safety tests were conducted in April 1986 which included 1) loss of flow without scram and 2) loss of heat sink without scram. Much of the original experiment data and design documents are no longer available. Effort should be made to properly catalog and document available EBRII documents before they are lost. 


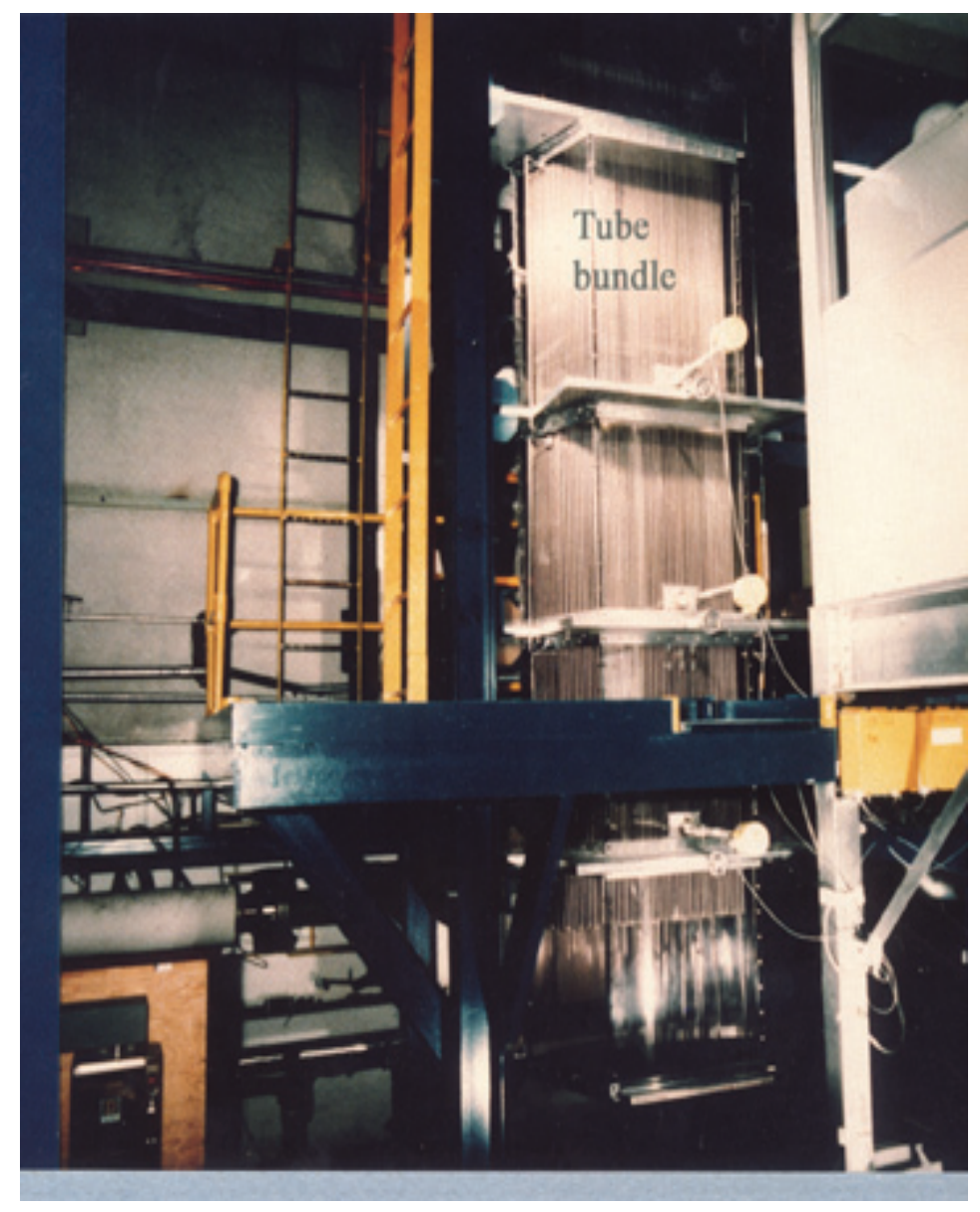

Figure 1. Example of a large separate-effects apparatus for the steam generator feedwater distribution and flooding experiments conducted at WRRTF. 


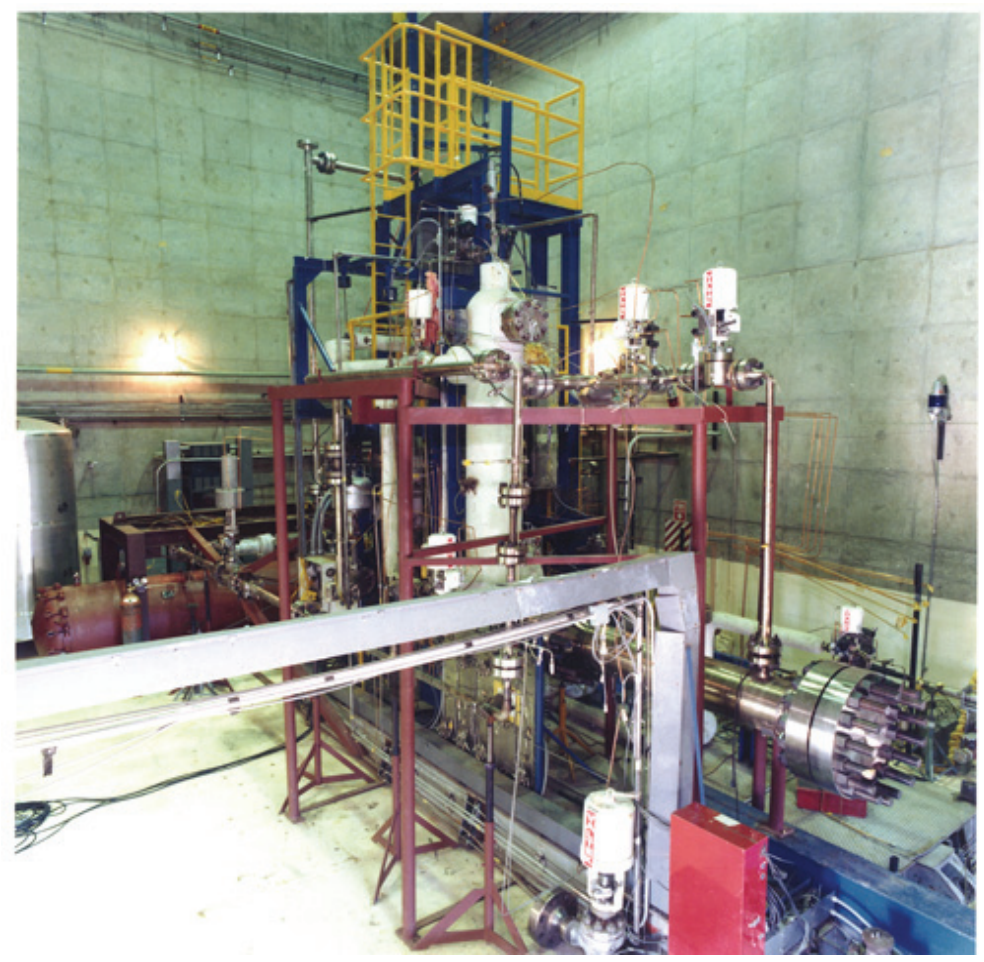

Figure 2. Steam-Air-Water (SAW) flow loop formerly located at WRRTF. Yellow ladder indicates size of apparatus. 
The TREAT reactor located at MFC was built to understand the behavior of fast neutrons during an excursion. The reactor was used to test candidate fuels for EBR-II and other fuels. The reactor has not been used since the Integral Fast Reactor (IFR) program was canceled in 1994. However, there are plans to restart the reactor for ABR fuel testing (Richter, e $t$ al., 2006). The Mark-III sodium loop shown in Figure 3 was installed in the TREAT reactor to provide sodium flow for fast reactor fuel testing.

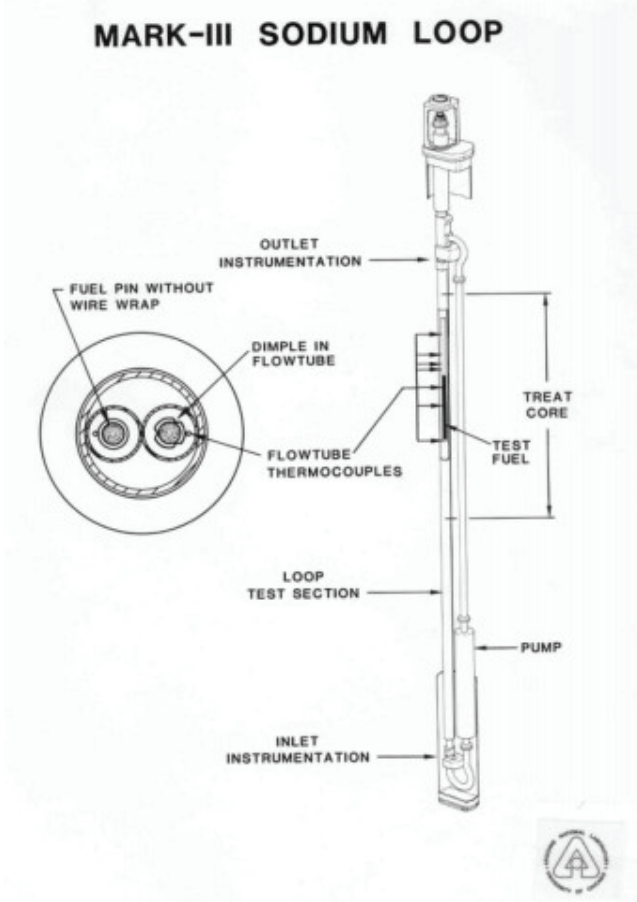

Figure 3. Sodium flow loop located in TREAT reactor. 


\section{III.2. Present Capabilities}

The Matched Index of Refraction (MIR) laboratory, located in-town at IEDF (IF 657) is the worlds largest such facility. The facility permits flow visualization and optical measurements within and external to complex flow passages that are made transparent by matching the index-of-refraction of models constructed of quartz with mineral oil that flows within and around to the models. The index matching is achieved by precisely controlling the mineral oil temperature (to within $\pm 0.05^{\circ} \mathrm{C}$ ). More information on the MIR flow loop is presented in Appendix 1, "Fast-Reactor Rod Bundle Matched-Index-ofRefraction Experiments".

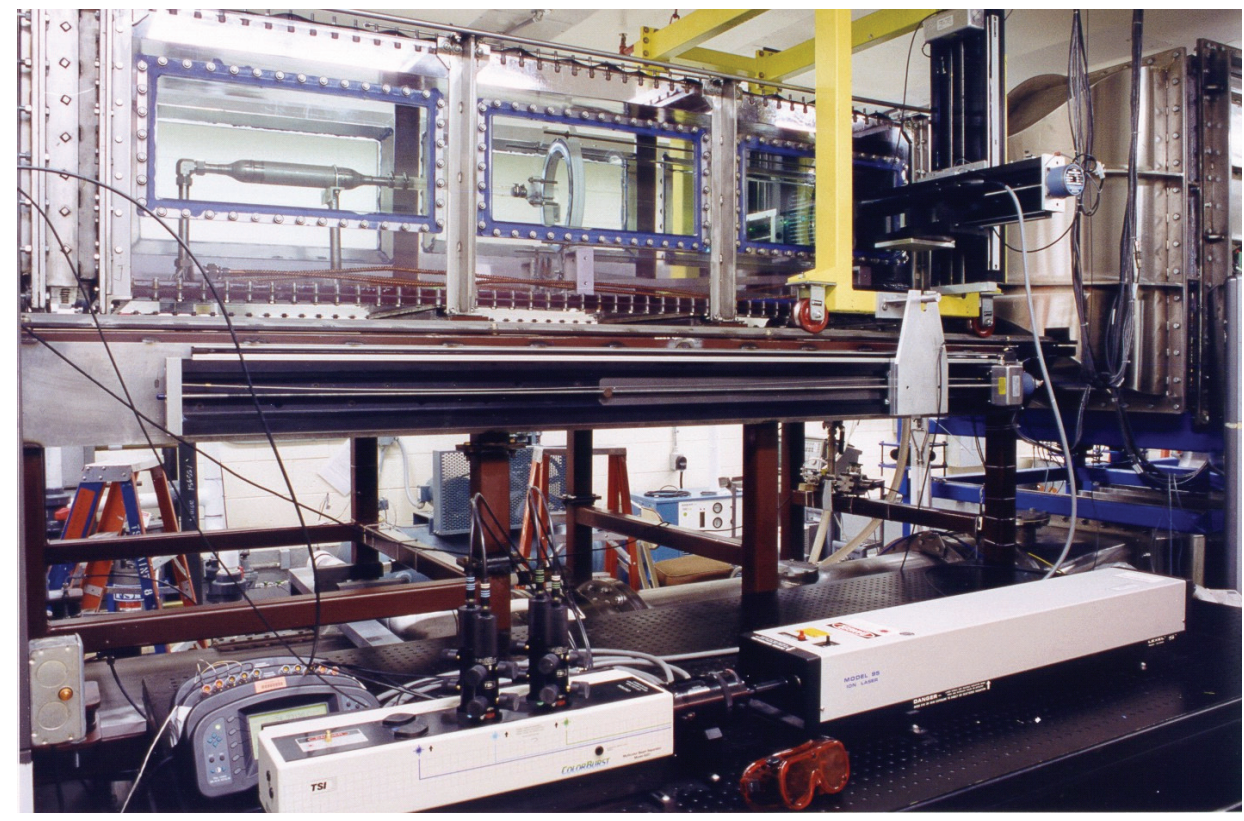

Figure 3. INL MIR flow loop showing test section, LDV system and 3D traversing mechanism (LDV and traverse are situated in yellow frame). 
As stated above, the May Street North Thermal Science Laboratory was relocated to BCTC Bay 9. There is an Independent Hazard Review (IHR) established for conducting small-scale thermal hydraulic experiments at the lab that use steam, air, or water as a working fluid. However, there are no thermal hydraulic experiments presently being conducted at the lab and space is mostly dedicated to the hydrogen fuel cell research project. There is room available in the lab for one or two bench-top size experiments.

There is a small NaK flow loop located in the MFC Engineering Laboratory that could be restarted for small-scale sodium or $\mathrm{NaK}$ fluid flow or, with installation of an electrically heated test section, heat transfer experiments.

\section{III.3. Present INL-University Collaborative Thermal Hydraulic Research}

The ISU Thermalhydraulics Laboratory (Prof Brian Williams PI) located on Skyline Avenue in Idaho Falls accommodates several experiments that are being conducted in collaboration with INL personnel who are pursuing advanced degrees. For example, a steam condensation water-hammer experiment is being conducted, in part, by Richard Schultz of the INL as a PhD dissertation project. The Skyline Avenue facility is the site identified for conducting collaborative research under a NERI-C proposal submitted in May, 2007 that would investigate VHTR lower and upper plenum flows during normal and pressurized conduction cooldown (PCC) scenarios titled "Scaled Experimental Modeling and Code Validation of VHTR Plenum Flows for Natural Circulation DecayHeat Conditions". The investigators are Prof. Brian Williams of ISU, Prof. John Crepeau of UI, Prof. Yassin Hassan of TAMU, and Dr. Glenn McCreery on the INL. The laboratory has sufficient floor space, electrical power, and (water) pumping capacity for the experiments. The INL Matched Index of Refraction (MIR) lab's Particle Tracking Velocimeter (PIV) would be used for velocity measurements in the experiments.

A reduced scale Gas Reactor Test Section (GRTS) capable of modeling a variety of important phenomena in a VHTR is being developed at Oregon State University in support of an INL Lab Directed Research and Development (LDRD) project (Theron Marshall, P.I.) titled, "Developing Core Flow Analysis Methods for the VHTR and GFR Designs". Prof. Jose Reyes is the primary OSU collaborator. The specific goal of the test facility is to produce benchmark data for Depressurized Conduction Cooldown (DCC) LOCA conditions.

An LDRD collaborative research project with MIT titled "Investigation of nanofluids for use in nuclear reactors" examines the usefulness of nanofluid coolants in nuclear systems by studying nanofluid materials suitable for nuclear reactor environments. Dr. Philip Sharpe of the INL is the P.I. and Prof. Jacopo Buongiorno is the MIT collaborator. MIT is investigating the heat transfer effects of nanoparticles in water. The INL part was to be the investigation of the heat transfer effects of nanoparticles in gas. However, the 
laboratory move from May Street North to BCTC led to moving the experiment to the STAR facility where delays due to contamination problems with the fume hood, power outages, etc. led to cancellation of the INL portion of the experiments. Another recently completed LDRD funded collaborative research project with MIT titled, "Fundamental Thermal-Hydraulic Phenomena in Advanced Gas-Cooled Reactors" investigated mixed convection heat transfer in gas-cooled fast reactors. An experimental facility, consisting of a natural and forced circulation driven closed-loop was constructed at MIT (Lee, et al., 2006). Richard Schultz of the INL was the P.I. and Dr. Pavel Hejzlar was the primary MIT collaborator. The research was successful and led to new correlations for the mixed convection heat transfer regime. The apparatus was initially intended to be moved to the INL at the completion of the research; however no facility was found to house the $7 \mathrm{~m}$ high apparatus and funding to move it was not available. 


\section{Path Forward}

Validation of code models will require benchmark experiments conducted in suitable facilities. A number of suitable experiments related to NGNP Very High Temperature Reactors (VHTR's), GNEP fast reactors, and light water reactors are presented as example experiments in this section. In addition, the INL has investigated GEN IV reactor concepts such as lead cooling and supercritical water (Wolf, 2007) that could be renewed if there is future interest. Costs of the example experiments presented vary from approximately $\$ 100 \mathrm{~K}$ to $\$ 300 \mathrm{~K}$ for building and conducting smaller separate effects experiments to approximately $\$ 3 \mathrm{M}$ for constructing a sodium-cooled rod bundle heat transfer apparatus to as much as $\$ 100 \mathrm{M}$ for building a large electrically-heated integral system.

Since there is no present laboratory facility, other than the MIR Laboratory, that is dedicated to conducting larger than benchtop thermal hydraulic experiments, new facilities need to be established. Preferably, facilities would include one laboratory dedicated to conducting experiments using sodium and one in-town laboratory dedicated to conducting experiments using relatively benign fluids. Experiments using sodium in any significant quantity should be conducted in a laboratory at MFC, where the infrastructure and facilities exist for handling sodium. Requirements for a suitable facility are discussed in section IV.2, "Sodium-Cooled Fast Reactor Thermal Hydraulic Experiment Program". A laboratory needs to be established for conducting small and large scale thermal hydraulics experiments using water, steam, gas, and other comparatively benign substances as the working fluids. The facility requirements would be similar to the features formerly available at the Water Reactor Research Test Facility (WRRTF), i.e., a high-bay laboratory with an overhead crane, and sufficient electrical power, water and air supply for the conduct of small to large scale experiments. The East wing of IEDF (IF 657) located in-town and described in the Candidate Buildings appendix (Appendix 3) of this report would be an excellent choice. This laboratory has the advantages of being located adjacent to IRC, is located in the same building as the MIR flow loop, has an overhead crane, and has adequate height (19 m), space and power. If a large electrically-heated integral system is contemplated for the future, the facility will require sufficient electrical power (several megawatts). Several suitable facilities, located at the site, are suggested.

\section{IV.1. VHTR Thermal Hydraulics Research}

A first order Phenomena Identification and Ranking Table (PIRT) for the VHTR was created by the INL for (1) normal operation, (2) pressurized conduction cooldown (PCC), and (3) depressurized conduction cooldown (DCC). Details of the PIRT are included in the NGNP Research and Development Plan (INEEL/EXT-05-02581), which was jointly issued by the INL, ORNL, and ANL. The PIRT was a preliminary characterization of important system behavior during PCC and DCC scenarios. A study by McEligot and 
McCreery, 2004, identified important thermal hydraulic phenomena during normal operation and the PCC scenario for a prismatic core design. Important thermal hydraulic phenomena (including DCC phenomena) are shown schematically in Figure 4. It appears, according to this study, that sufficient heat transfer benchmark data are available to assess correlations for systems codes for the ranges of expected normal operating conditions in the coolant channels of a prismatic core design. For the PCC scenario, further core channel heat transfer experiments may be needed to cover possible ranges of hypothesized accident scenarios (such as mixed convection heat transfer) and for detailed assessment of proposed turbulence models for CFD codes. Important thermal hydraulic phenomena relate to flows in the upper and lower plenums of a VHTR (in both prismatic core and pebble-bed designs). Proposed experiments are described that study these phenomena. DCC phenomena of importance include air ingress and the displacement of helium coolant, resultant air natural circulation, and core conduction and radiation heat transfer. These phenomena are proposed to be studied in the INL LDRD sponsored Gas Reactor Test Section (GRTS) for a prismatic core design. The preliminary design and scaling analysis of the apparatus was conducted at Oregon State University (Reyes, et al., 2007). A simplified air ingress experiment, without the complications of thermal nonequilibrium, is described below. Possible core heat transfer and turbulence experiments are also described for a prismatic core coolant channel. 


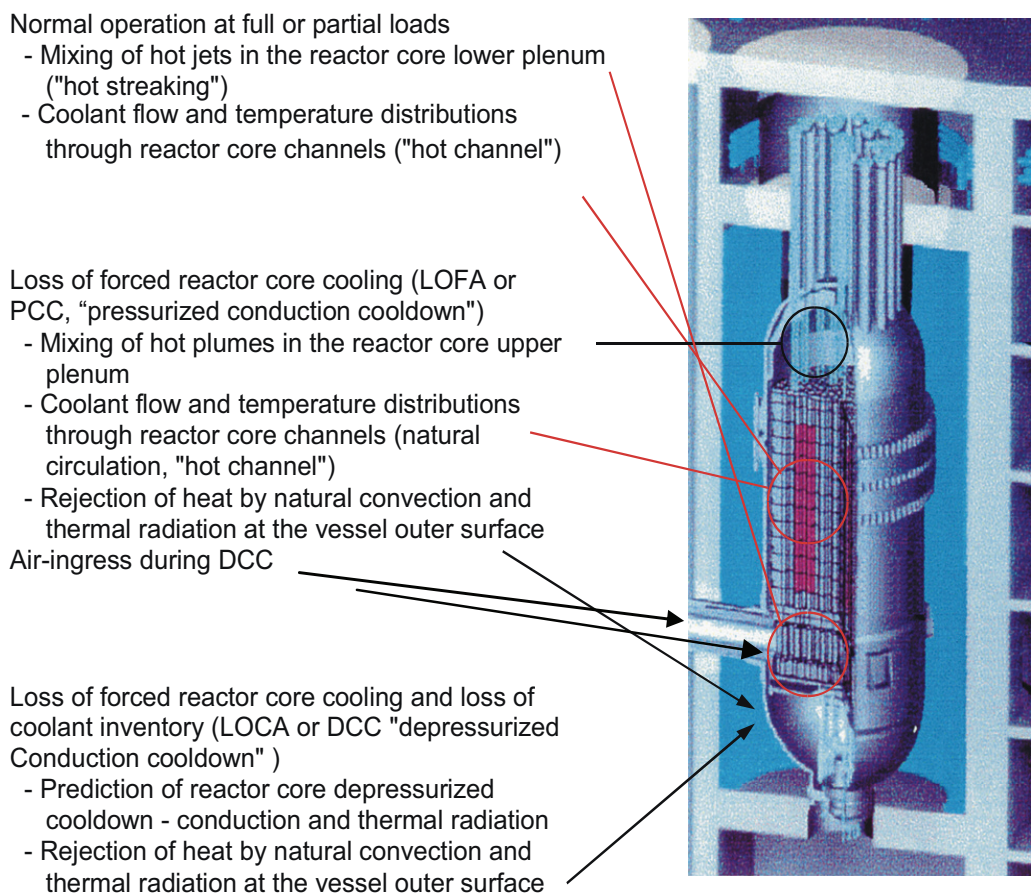

Figure 4. Important VHTR thermal hydraulic phenomena. 


\section{IV.1.1. Upper and Lower Plenum Experiments}

Experiments were designed in 2006 (McCreery and Condie, 2006) to model upper and lower plenum flows during normal and pressurized conduction cooldown conditions. Geometrically scaled models of the plenums are employed with heated water flow. A schematic of the prismatic core lower plenum model is shown in Figure 5. Water temperatures are scaled to match Richardson number (the ratio of gravity to inertial force) and flow rate is adjusted to match Reynolds number (the ratio of inertial to viscous force). The models may be adapted to either prismatic or pebble bed core designs. The experiments might be either conducted in a new facility at the INL or at a university laboratory. A NERI-C proposal was submitted in May 2007 to conduct the research at the ISU Skyline Thermal Hydraulics Laboratory (submitted by Brian Williams, ISU, John Crepeau, UI, Yassin Hassan, TAMU, and Glenn McCreery, INL). 

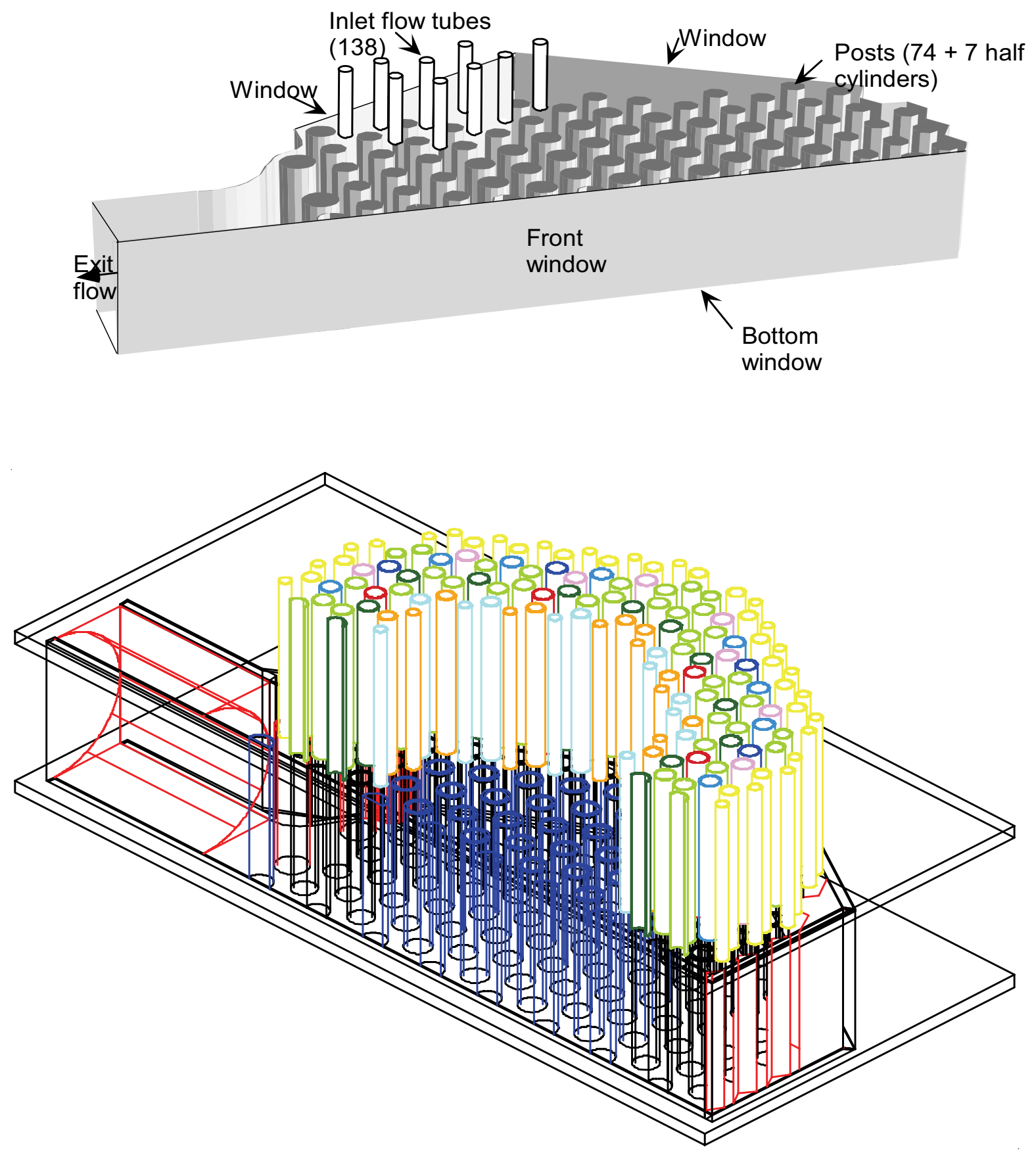

Figure 5. Isometric schematic of lower plenum model and view showing construction details including posts, outlet nozzle, top and bottom sheets, windows, and inlet tubes. 


\section{IV.1.2. Air-Ingress Experiment}

In the event that a VHTR experiences a large-break LOCA in a component external to the reactor vessel, the vessel will eventually depressurize sufficiently to allow air ingress into the hot duct. The onset of air-ingress is accompanied by the intrusion of a "nose" of cold air that enters at the bottom of the hot duct and displaces lower density helium, which flows countercurrent along the top of the hot duct according to Reyes, et al., 2007.

The proposed experiment, shown in Figure 6, is a first-step in quantifying the air-ingress scenario for code validation purposes. The experiment is being designed in collaboration with Richard Schultz of the INL and Dr. James Liou of the University of Idaho, Moscow, Idaho. The problem is simplified by ignoring the temperature difference between the cold air and the hot hydrogen in the lower plenum and heat transfer to the lower plenum components (oxidation of support posts and core channels is the key safety question associated with air ingress). Room-temperature helium and nitrogen are used to represent hot hydrogen and cold air and to provide the density difference that drives air-ingress phenomena. The lower plenum geometry is simplified by a rectangular cross-section representation; the representation used in the lower-plenum flow MIR experiments. It may be possible to incorporate the actual MIR lower plenum model in the apparatus if the scale of the model (1:6.55) and the transparency of the model are found to be suitable (transparency might be improved by substituting thin-wall glass tubes for the solid quartz rods that represent support posts in the lower plenum). Initially, the simulated support posts could be removed to provide the simplest-case air-ingress problem for code simulation. The nitrogen and helium are initially contained in separate chambers and separated by a slide or gate valve. The initial pressures of the nitrogen and helium are atmospheric or, alternately, the helium may be pressurized by use of a helium gas cylinder connected through a pressure-regulator to the helium chamber. An experiment is initialized by quickly opening the slide valve. Helium depressurization and subsequent nitrogen-ingress will then commence.

Instrumentation will consist primarily of the MIR laboratory 3D PIV system. Small (submicron) olive-oil drops will be suspended in the nitrogen and be used as the tracer particles for PIV. 3D velocity profiles will thereby be generated. Concentration maps will also be generated by using laser-induced fluorescence (LIF). A fluorescing medium, such as acetone vapor, will be mixed with the nitrogen. The intensity of fluorescence is directly proportional to the nitrogen concentration across the laser light sheet (accounting for the one over radius squared decrease in laser light sheet intensity). Nitrogen-helium diffusion may thereby be quantified. LIF is an extension of PIV in that it uses one PIV camera (one camera since this is a 2D measurement rather than 3D) and the LaVision PIV software (plus a LIF addition). LIF requires an additional camera filter to isolate the fluorescing wavelength from the scattered laser light wavelength. A new laser is required to fluoresce the acetone molecules for LIF. A $50 \mathrm{~mJ} / \mathrm{pulse} 266 \mathrm{~nm}$ ultraviolet laser is recommended by Steve Anderson of LaVision. In addition, an image intensifier 
is required for the PIV camera. The upgrades for the present PIV system to permit PIV of gas flow and LIF will cost approximately $\$ 100 \mathrm{~K}$

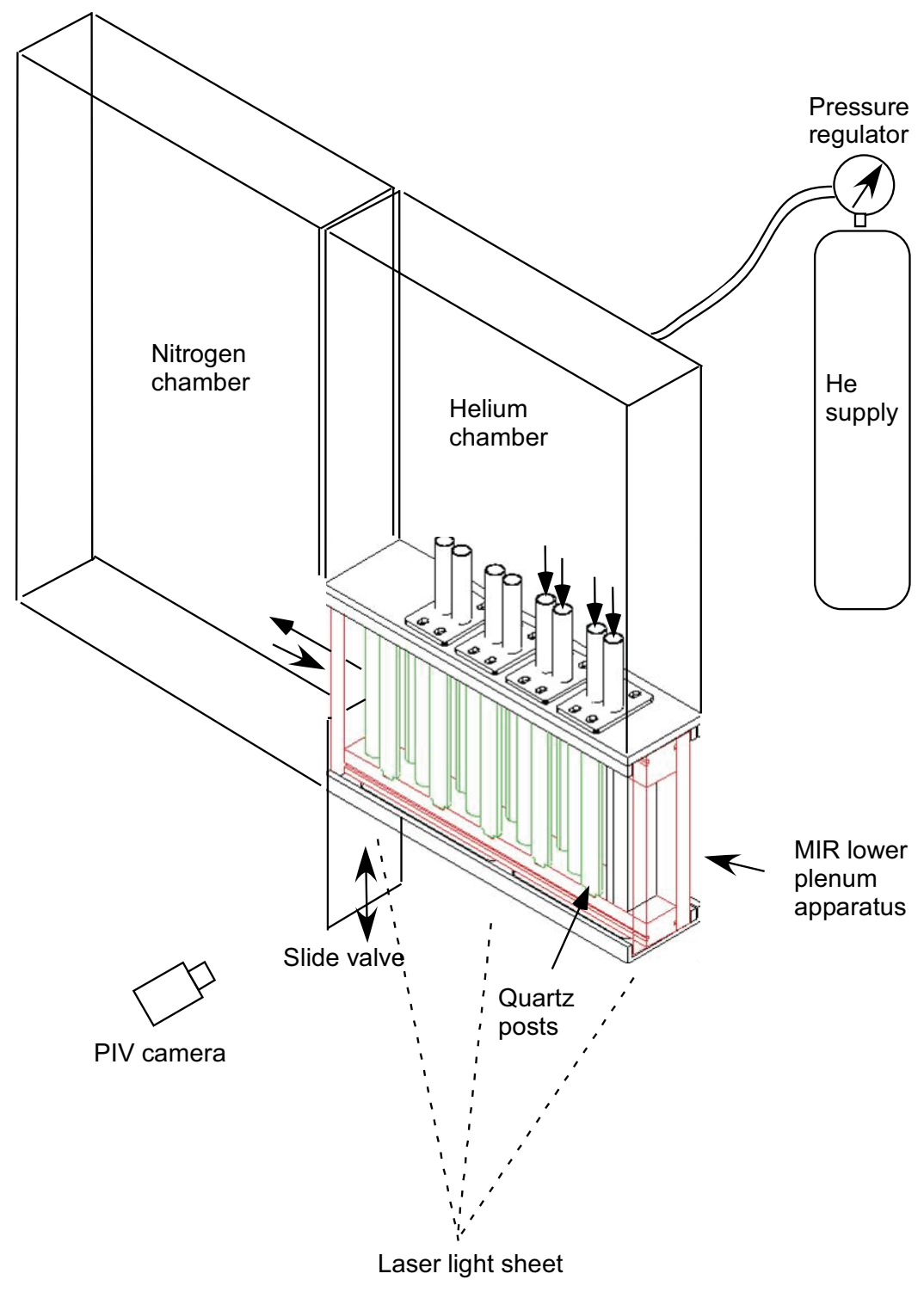

Figure 6. Isothermal air-ingress experiment apparatus 


\section{IV.1.3. Core Heat Transfer And Turbulence Experiments}

This study would concentrate on examining the effects of property variation for the circular tube geometry of the prismatic core design or the core flow of the pebble bed design. The general goal would be to obtain greater understanding and data for code validation of the structure of strongly-heated, internal, turbulent gas flows, with an emphasis on turbulence structure. Turbulence modeling validation requires measurements of the basic quantities of their governing partial differential equations for assessment, quantities such as turbulence kinetic energy and Reynolds stresses, $\overline{v^{2}}, \overline{u v}$, etc. These data generally have not been available for strongly-heated internal flows. Hence, objectives are to measure heat transfer rates and the fundamental turbulence structure, and to obtain benchmark data to assess CFD codes for high temperature gas flows that are predominantly in the forced convection region, for a range of conditions important in VHTR reactors (which may include mixed convection).

The experiments would extend the existing methods of McEligot and Prof. J. M. Wallace of U. Maryland and their colleagues. The probes developed by Profs. Wallace and Vukoslavcevic in a recent KNERI project (McEligot et al., 2002) would be employed at INEEL to measure fluctuating velocity components and temperature in high temperature gas flow through a vertical circular tube for assessment of the predictions and to understand the fundamental effects of this heating on the physics of the flow.

Initial experiments might be conducted using an open flow system incorporating a vertical, resistively-heated, circular test section exhausting directly to the atmosphere in the laboratory or, for lower flow rates, a closed-loop system similar to that used to study mixed convection in the INL LDRD sponsored experiments conducted at MIT (Lee, et al., 2006). A more versatile circular tube apparatus as shown in Figure 7, could be developed with sufficient funding. The experiment would initially provide an approximately uniform wall heat flux boundary condition in a tube for helium. The apparatus could eventually be modified to simulate variable heat flux in space and time. Controlled wall heat flux would be provided with a stable electrical power supply. The heated length would permit high heating rates with Inconel as the tube material while approaching developed conditions. The miniature multiple-sensor hot-wire probes from Prof. Wallace and Vukoslavcevic would be inserted through the open exit to obtain pointwise temperature and velocity measurements. 


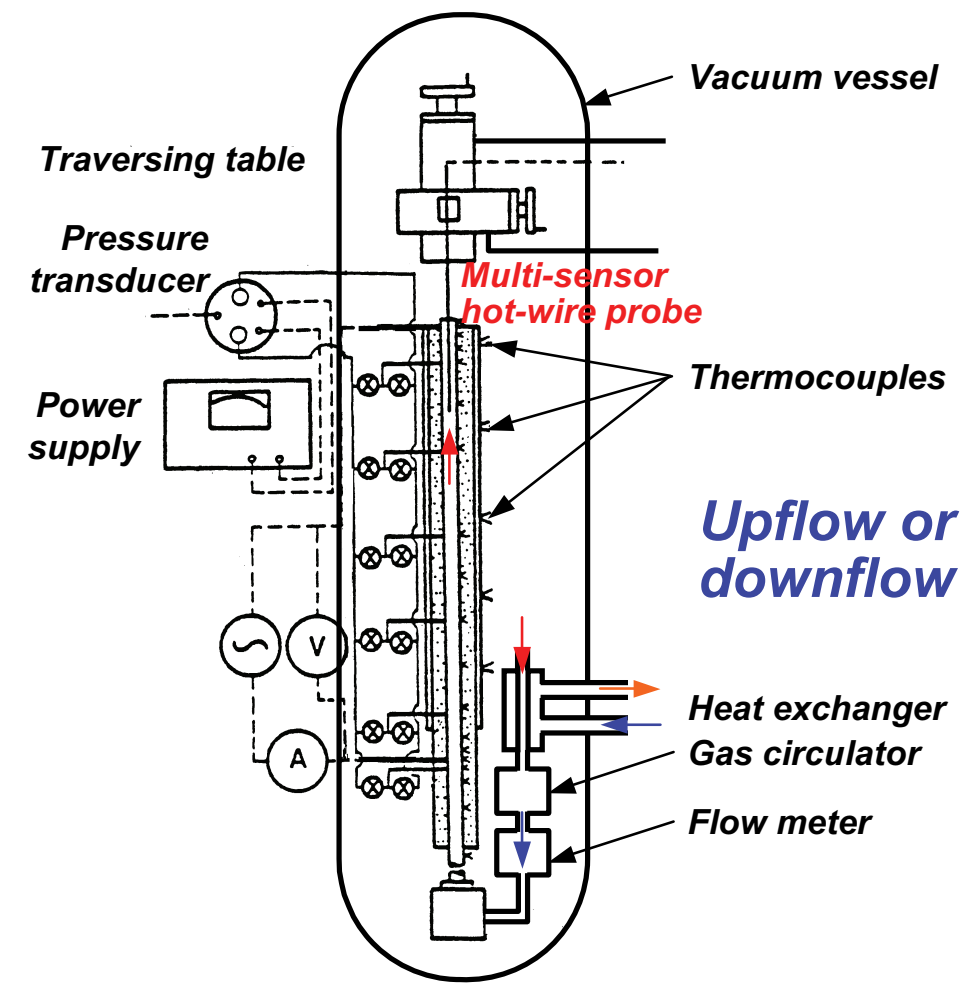

Figure 7. Potential apparatus to obtain benchmark heat transfer and turbulence data in heated channel flow

\section{IV.1.4. Electrically-Heated Integral VHTR Facility}

Electrically heated light-water reactor integral facilities, discussed in section IV.3.2, have proven to be of considerable value for providing code validation data for a large variety of accident and off-normal operation scenarios. A large-scale electrically-heated VHTR facility could be used to study a variety of PCC and DCC scenarios. The INL LDRD funded design and scaling analysis of the Gas Reactor Test Section (GRTS) conducted at Oregon State University (Reyes, et al., 2007) might be a suitable starting point for the scaling and design of a more comprehensive (and larger) facility.

\section{IV.2 Sodium-Cooled Fast Reactor Thermal Hydraulic Experiment Program}

A thermal hydraulic experimental program is needed to support fast reactor development in the GNEP program. All GNEP modeling and simulation tools must be demonstrated to be accurate and reliable through a formal V\&V process. Benchmark data will be needed to validate models of flow and heat transfer in the reactor core, in the sodium filled vessel pools, and in the remaining primary and system. Experiments that model core flow are proposed to be conducted in the INL Matched Index of Refraction (MIR) flow loop. The experiments, which are necessarily conducted under isothermal conditions, complement 
heat transfer experiments to be conducted in a sodium-cooled rod bundle heat transfer facility. Although heat transfer may be measured accurately in such a facility, velocity measurements are more problematical. Instrumentation development, and especially ultrasonic velocity meter development, is proposed to help improve velocity measurements in a hot sodium environment. Restarting an existing liquid metal flow loop located at MFC is proposed to help with the instrumentation development. Finally, an experimental facility for the investigation of flow and heat transfer in sodium pools is addressed.

\section{IV.2.1. Matched Index-Of-Refraction Rod Bundle Experiment}

Experiments are proposed to be conducted in the INL Matched Index-of-Refraction (MIR) Flow Facility to characterize the three-dimensional velocity and turbulence fields in a wire-wrapped rod bundle. The model will be constructed of quartz components and the working fluid will be mineral oil. The model will be a scaled 7-pin rod bundle enclosed in a hexagonal duct constructed from fused quartz plates. Flow field velocity measurements will be obtained with a 3-D particle image velocimeter (PIV) and local velocity and turbulence measurements will be obtained using a 2-D laser-Doppler Velocimeter (LDV). Details of the MIR experiment preliminary design and a cost estimate for the apparatus construction are presented in Appendix 1. The MIR experiments compliment experiments to be conducted in the sodium-cooled rod bundle heat transfer facility discussed below in that they will provide accurate three-dimensional velocity measurements within in bundle as opposed to, at best, only a few average velocity measurements in the sodium-cooled rod bundle. However the MIR experiments will provide no heat transfer measurements since the experiments will necessarily be isothermal. The MIR experiments will be considerably less expensive to implement and have a much shorter lead time than sodium-cooled heat transfer experiments since the sodium-cooled rod bundle facility must first be designed and built before experiments are conducted.

\section{IV.2.2. Sodium-Cooled Rod Bundle Heat Transfer Facility}

The objective is to develop a facility capable of characterizing heat transfer for a wirewrapped rod bundle for natural convection, mixed convection, and forced convection for normal, off-normal and accident conditions. Measurements need to be of sufficient accuracy and quantity for code validation. Two schematics of a suitable flow loop are shown in Figures 8 and 9 . The simulated fuel rods in the bundle would be electrically heated and contain thermocouples embedded within the rods and in contact with the inside of the rod cladding, similar to the THORS fuel rod simulator design shown in Figure 10 (Gnadt, P.A., et al., 1984). Conversations with Gordon Hadaller of Stern Laboratories, Hamilton, Ontario, Canada, indicate that approximately ten thermocouples per rod are the maximum number that may be embedded in a rod with a typical fast reactor fuel rod diameter of 0.25 to 0.3 in. (Stern Laboratories is the sole remaining 
company in North America with that experience and capability of manufacturing electrically-heated fuel rod simulators.) Preliminary calculations indicate that a flow rate of approximately 26 GPM is needed to insure fully-turbulent flow with a Reynolds number of 22,000. Loop pressure drop will be approximately 3 psi. These flow and pressure drop conditions may be reasonably achieved using one of the EM pumps available at MFC according to conversations with Dan Wachs. This maximum Reynolds number is achieved at an average bundle velocity of approximately $2.15 \mathrm{~m} / \mathrm{s}$. If the maximum velocity were to be increased to a typical prototype value of approximately 8 $\mathrm{m} / \mathrm{s}$ then the pump flow rate would be approximately 97 GPM with a loop pressure loss of approximately $50 \mathrm{psi}$ or greater. This would probably require the design and construction of a new EM pump. A reasonable maximum power to be delivered to a fuel rod simulator is approximately $10 \mathrm{~kW}$ (this value is comparable to the thermal power produced by an EBRII fuel rod during normal operation of approximately $15 \mathrm{~kW}$ ). Total maximum core power for a 19 rod bundle would then be approximately $190 \mathrm{~kW}$. Power should be delivered to the fuel rod simulators as direct-current (DC), in order to reduce instrumentation noise (a lesson learned from the Semiscale program), and at a voltage of approximately $300 \mathrm{~V}$. Lead time for construction of the fuel rod simulators is approximately six to nine months, according to Stern Laboratories.

It would be necessary, or at least desirable, to measure the velocity distribution within the bundle or across the bundle exit for code validation purposes. However, this is a formidable challenge as discussed below in "Instrumentation Development".

Jim Werner of the space nuclear power program has expressed interest in the heat transfer facility since the design of the lunar deployed nuclear reactor would use similar fuel bundles as a terrestrial fast reactor. Dan Wachs has also expressed interest in the facility since he is testing an EM pump in collaboration with NASA Marshall. Building the experiment and upgrading the identified building (the Sodium Boiler building at MFC) could therefore be a collaborative (and cost sharing) effort. 


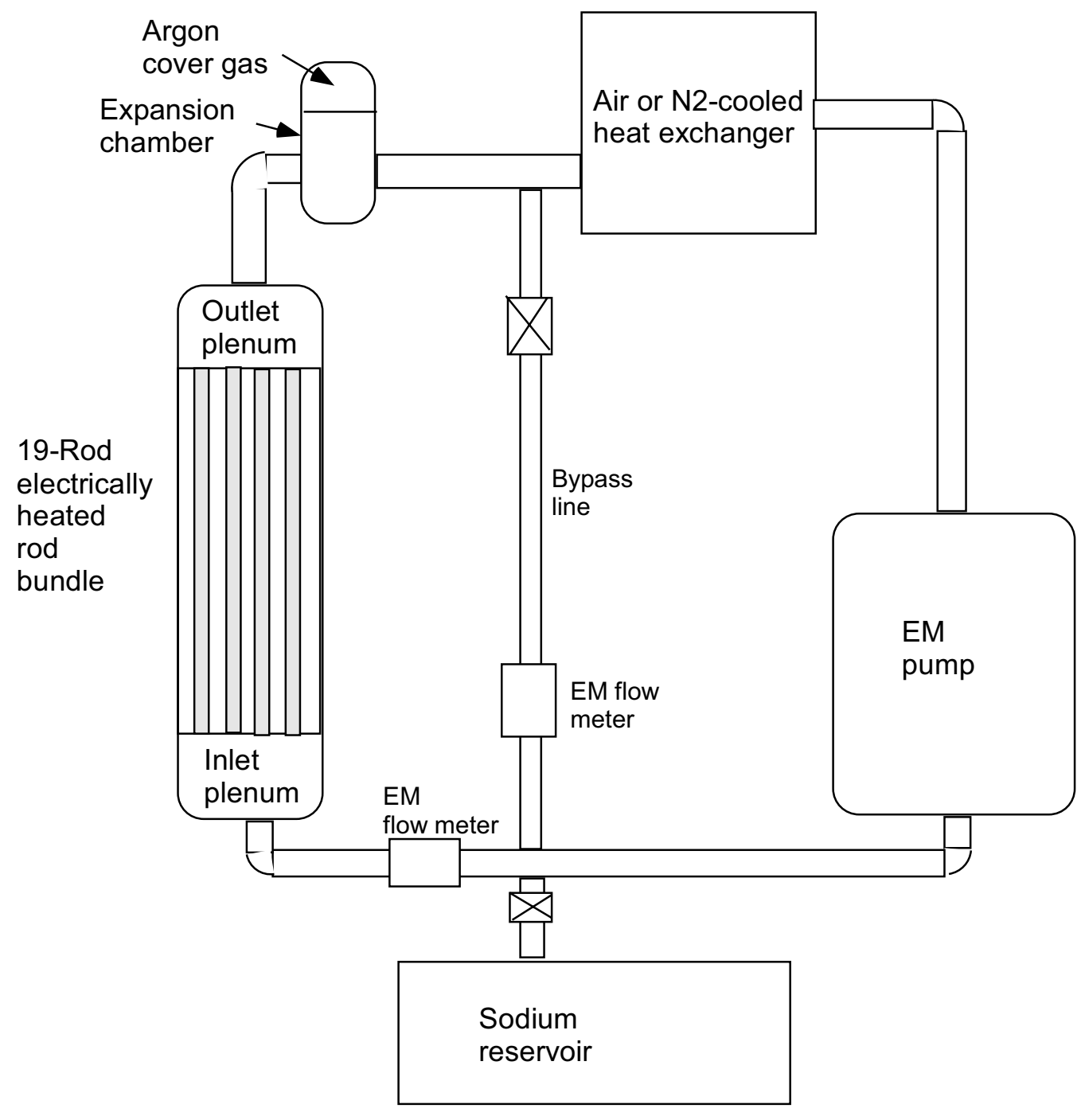

Figure 8. Schematic of 19 rod bundle sodium-cooled heat transfer experiment

Features

- Wire-wrapped electrically heated rods instrumented with embedded TCs

- Uses existing EM pump

- $\quad$ Bundle flows range from low (typical of natural circulation) to fully turbulent (Reynolds numbers $>20,000$ ) 


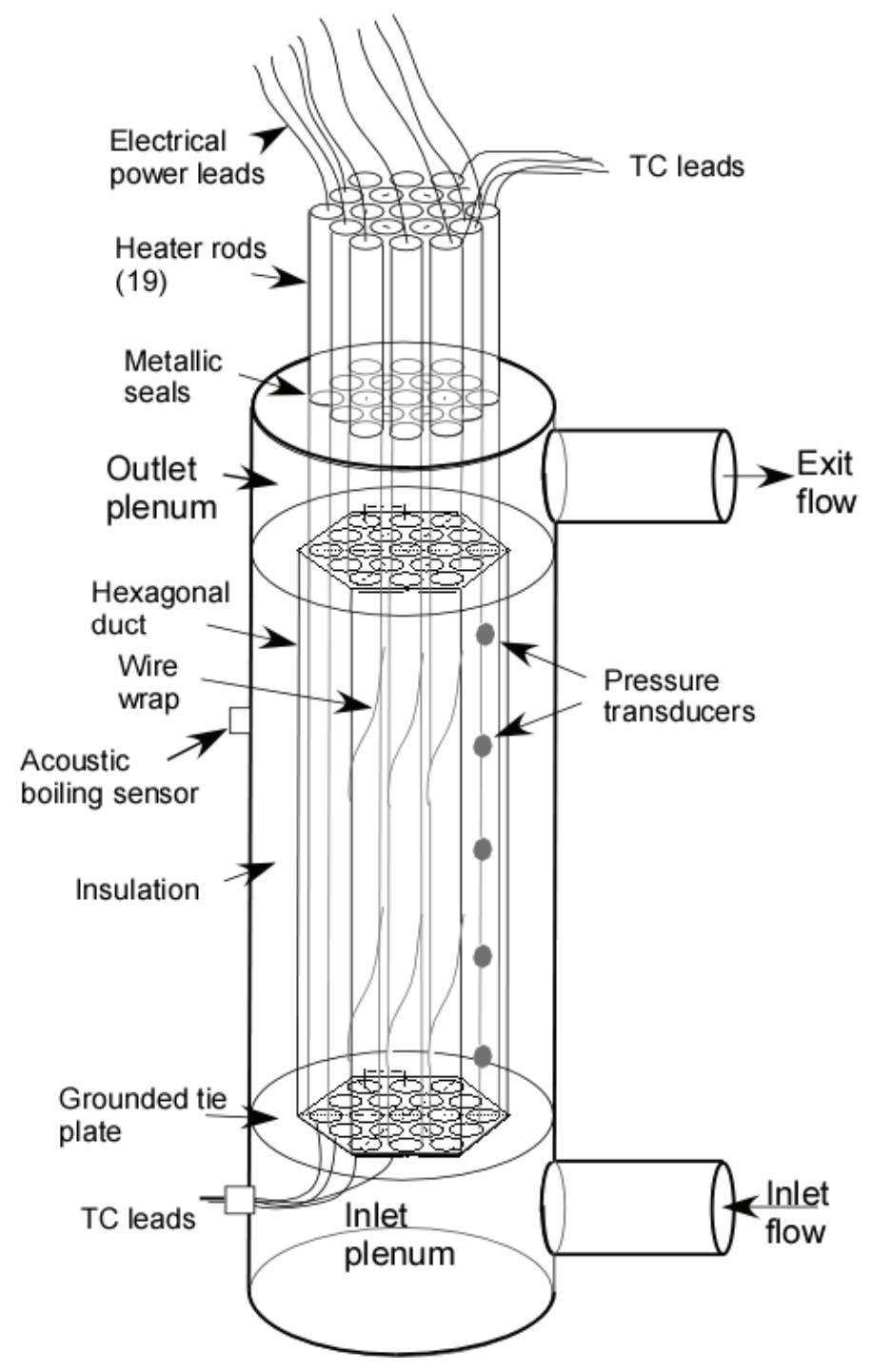

Figure 9. Sodium-cooled rod bundle test section. 


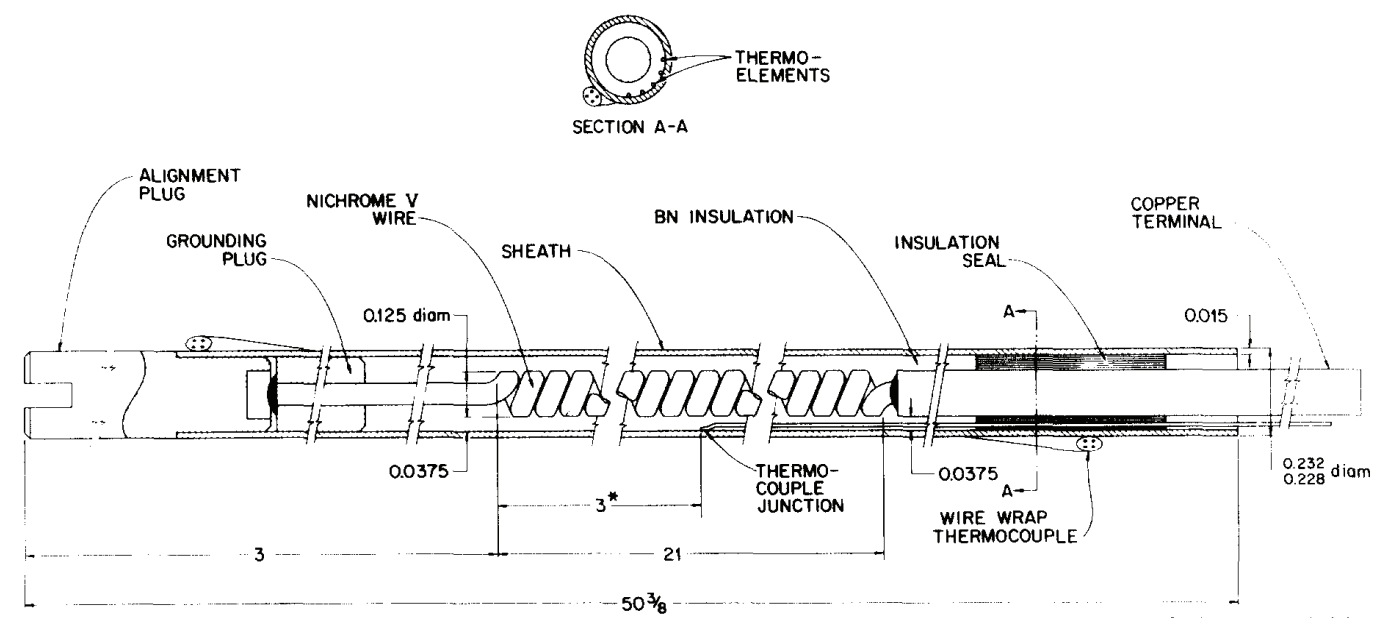

* may vary from 3 in. -11 k in.

DEPENDING ON TYPE OF FUEL PIN SIMULATOR

Fig. 8. FPS for THORS Bundle $3 \mathrm{C}(1 \mathrm{in}=25.4 \mathrm{~mm})$.

Figure 10. Typical fuel rod simulator from the THORS facility. 


\section{IV.2.3. Restart Of The Nak Flow Loop Located In The MFC Engineering Laboratory}

The small flow loop located in the MFC Engineering Laboratory and shown in Figure 11, would be very useful for conducting small-scale fluid flow and, with the addition of an electrically heated test section, heat transfer experiments using sodium. The loop, situated in an inert gas (argon) glove box, could be operational long before a new sodium-cooled rod bundle heat transfer facility was constructed. The loop could be used for instrumentation development, such as for development of an ultrasonic velocity meter, and other tasks in support of the new heat transfer facility. Also, by incorporating a single fuel rod simulator and an air-cooled heat exchanger it could be used for singlerod heat transfer experiments. Contact: Dan Wachs.

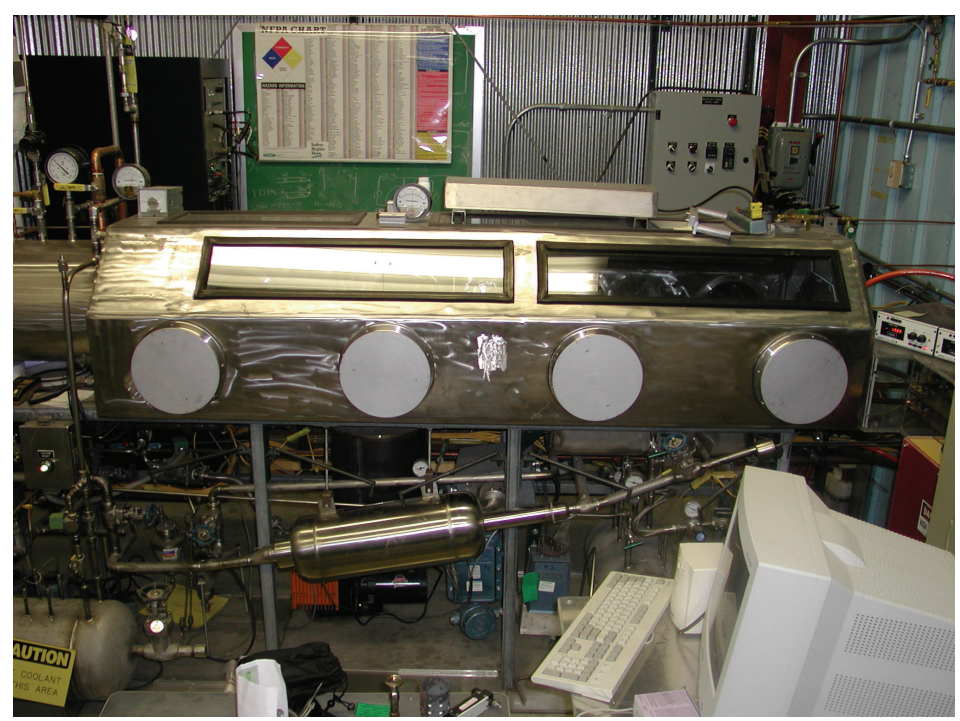

Figure 11. NaK flow loop located at the MFC Engineering Laboratory.

\section{IV.2.4. Sodium Pool Natural Circulation Facility}

The objective would be to develop a facility capable of characterizing flow and heat transfer in sodium pools. The facility could also be used to characterize natural convection in models of shutdown heat removal systems. Experiments would be conducted in geometrically scaled models of fast reactor pools under natural convection heat transfer and flow conditions. The fluid would likely be sodium, $\mathrm{NaK}$, or another low Prandtl number liquid metal and with experiment conditions scaled to natural convection in prototype geometries. Scaling requires matching Reynolds and Richardson numbers for hydrodynamic similarity and Peclet number (energy convected/energy conducted) for 
thermodynamic similarity in steady-state experiments. (Water is not a suitable medium because of large Peclet number distortions). For transient experiments, fluid-structure heat transfer also needs to be addressed. For a small-scale facility, the relevant time scales are reduced and wall materials will need to be chosen in order to scale the relevant thermal parameters; primarily Biot modulus (convection heat transfer/conduction heat transfer). It may be difficult or impossible to scale both the hydrodynamics and the fluidstructure heat transfer mechanisms for transient problems without significant scaling distortions, according to Heisler and Singer, 1981. However, the time-reduced heightreduced scaling methods used to design integral PWR experiments, as discussed in Appendix 4. "Scaling approaches for light-water electrically-heated integral facilities", might point to a valid scaling approach for transient natural convection in pools.

Measurements need to include both temperatures and velocities of sufficient quantity and quality for code validation purposes. Temperature measurements are easily obtainable using thermocouples. However, velocity measurements will require improvement in the state of the art, as described in the following section, "Instrumentation Development". Velocity measurements will be more easily obtained in a pool than within a rod-bundle because of the larger volume available for a probe.

\section{IV.2.5. Instrumentation Development}

Advanced instrumentation, such as ultrasonic velocity meters, needs to be developed for implementation in sodium flow thermal hydraulics experiments in order to provide the measurements necessary for code validation.

Considerable effort will be needed to develop instrumentation capable of accurately measuring velocities in sodium flow. It is desirable to have both local 3D velocity components and turbulence measurements for code validation comparisons. However, velocity measurement in liquid metals is very difficult and past experiments using sodium, such as those that modeled natural convection, report only local temperatures not velocities. For example, Ishitori, et al., (1987) performed an experimental study of sodium natural convection in the intermediate plenum for pool-type LMFBRs and compared measured temperatures with numerical predictions. They conclude that "The temperature distributions indicate good agreement between experimental and numerical results", even though a separate comparison of velocities would normally be required for proper code validation. Rosen and Ribando (1981) performed a numerical study of expansion tank flow in the thermal-hydraulic out-of-reactor safety (THORS) facility although only temperatures were available for comparison. The computer model employed the Boussinesq approximation and simple turbulence models to simulate the flow. Without velocity measurements it would be difficult or impossible to validate the separate assumptions and turbulence models employed.

Widely used methods for velocity measurements in other fluids than liquid metals are not suitable for several reasons. Optical methods cannot be applied because of the opacity of 
liquid metals. Hot wire and hot film sensors do not work beyond fluid temperatures of approximately $100^{\circ} \mathrm{C}$. Pitot tubes are troubled by the solidification of the liquid metal and only give values for the local mean velocity component. Methods for measuring velocity by permanent magnet probes is described by Ricou and Vivies (1982) and by Weissenfluh (1985) whereby the electromotive force induced in a liquid conductor (e.g. sodium) moving through a magnetic field is used. However, the probe is intrusive and produces reliable results only if the spatial temperature distribution is approximately linear near the probe. A promising recently developed method is Acoustic Doppler Velocimetry (ADV), which was used by Eckert, et al. (2003) to measure flow velocities at temperatures up to $620 \mathrm{C}$ in liquid sodium. Thermal restrictions were overcome by using a piezoelectric transducer coupled to wave-guide probe. Two or three-dimensional velocity components may be obtained by using an array of ADV sensors. There is a current NERI project to investigate ultrasonic measurements in sodium titled "Experimental Development and Demonstration of Ultrasonic Measurement Diagnostics for Sodium Fast Reactor Themohydraulics" by Professor Akira Tokuhiro of Kansas State University. Interestingly, Professor Tokuhiro has accepted a position at the University of Idaho Mechanical Engineering Department in Idaho Falls. He has expressed interest in collaborating with INL personnel on instrument development after he arrives in August, 2007. 


\section{IV.3. Light Water Reactor Research}

A new thermal hydraulics laboratory needs to be commissioned before any significant new light water reactor research can be conducted at the INL other than benchtop scale experiments and through university collaboration. The laboratory should be equipped with single-phase water and two-phase water and air-water flow loops. Ideally, the twophase flow loop would be an updated version of the Steam-Air-Water (SAW) loop that was formerly located at WRRTF (Figure 1). A blowdown facility, such as that formerly located at WRRTF, could also be built if critical flow in components is to be studied. Although the WRRTF facility has been demolished, it can serve as example for upgrading a suitable facility at the INL for conducting light-water experiments. In addition to separate effects experiments conducted in components such as a steam generator, lower and upper plenum, pump, rod bundle, etc., there are many phenomena that have not been characterized sufficiently for code validation purposes. There are many examples of correlations developed in bygone decades that rely on data that is no longer available or, if available, of insufficient quality for validation purposes. And even the best data obtained in the 1960s and 1970s, when funding for LWR research was relatively abundant, could be improved by repeating the experiments using modern instrumentation. This is especially true of fluid dynamic phenomena, where the advent of laser Dopler anemometry (LDA) and particle-image velocimetry (PIV) have greatly advance the state of the art.

\section{IV.3.1. Light Water Reactor Phenomena}

A partial list of light-water thermal hydraulic phenomena of interest to code validation is listed in Table 1. Transient two-phase flow is important in a variety of light-water reactor thermal-hydraulics problems. Validation of mechanistic models for the interfacial transport of mass, heat and momentum requires measurements that are both localized and transient. The problem is complicated because the form of the models may depend on, for example, interfacial areas which in turn are dependent on flow regimes. Good mechanistic models of flow regimes are still not available for complex geometries and transient situations. 
Table 1. Light-water reactor thermal hydraulic phenomena of interest to code validation

Fluid-dynamic

Turbulence

Mixing

Thermal stratification

Flow Instabilities

Parallel-channel effects

Flow transients and LOCA's

Two-phase flow phenomena

Flow regimes and transitions

Interphase forces

Entrainment

Mixing

Cavitation

Pressure loss

Interfacial area evolution

Heat transfer

Forced convection

Natural convection

Mixed convection

Radiation

Conduction

Convection plus axial conduction in sodium channel flow

Two-phase evaporation and condensation

Boiling

Thermal striping (random thermal cycling of a component by a flow stream resulting from mixing of flow streams of different temperatures)

Fluid-structure interactions

Pressure

Pressurized thermal shock

Pipe break reaction force and jet load

Flow induced vibration

Water hammer

Cavitation effects (e.g. surface erosion) 


\section{IV.3.2. Electrically-Heated Integral Facility}

An electrically heated integral facility, such as Semiscale (described in section III.1, "Historical capabilities") could be built if the need and funding were sufficient. However, the electrical power of any existing in-town facility is insufficient for the several megawatts required for a full-height full-pressure integral facility. Several facilities are located at the site that meet the space and power requirements. One building is the EBRII Power Plant (MFC 768), which has sufficient height, floor area, an overhead crane, and sufficient electrical power $(20 \mathrm{MW})$ for a full-height integral facility. Another building located at MFC is the Sodium Processing Facility (MFC 799). The facility has been used to process sodium from EBRII for disposal by converting it to sodium hydroxide. The facility would need to be declassified as an EPA Resource Conservation and Recovery Act (RCRA) controlled facility to be useful for research use without onerous restrictions. Unused high-bay facilities located at INTEC, and listed in Appendix 3, might also be suitable for an integral PWR model facility. The INTEC buildings are owned by CWI which might impose more difficulties than using a building owned by Battelle. There are alternate scaling approaches than the "full-height full-pressure" rational used to design Semiscale that might be employed and are described briefly in Appendix 4, "Scaling approaches for light-water electrically-heated integral facilities". If the future possibility of constructing a full-height-full-pressure integral facility is not foreseen then other lower-height (and lower power) facilities could be employed for reduced-height integral system testing.

\section{IV.3.4. ATR Flow Loop}

It has been suggested that an unheated water flow loop located at RTC would be useful for characterizing ATR fuel bundle pressure losses and vibration characteristics prior to the fuel being used in ATR. Having the loop located at ATR would simplify fuel transportation problems.

\section{IV.3.5. Reactivity feedback thermal hydraulic experiment}

The objective of this proposed experiment is to study the thermal hydraulic effects of reactivity feedback using an electrically heated fuel rod simulator composed of a stack of individual cylindrical heaters. A simplified, time-dependant, model of reactivity feedback, such as used in RELAP5 and other codes, is,

$Q_{i}=Q_{0 i}+k 1\left(T c_{i}-T c_{0 i}\right)+k 2\left(T s_{i}-T s_{0 i}\right)$

Where,

$\mathrm{Q}_{\mathrm{i}} \quad=$ heat input to rod segment $\mathrm{i}$

$\mathrm{Q}_{0, \mathrm{i}} \quad=$ initial heat input into rod segment $\mathrm{i}$ 


$$
\begin{aligned}
& \mathrm{k} 1, \mathrm{k} 2=\text { constants (positive or negative) } \\
& \mathrm{Tc}_{\mathrm{i}}=\text { coolant temperature associated with segment } \mathrm{i} \\
& \mathrm{Ts}_{\mathrm{i}}=\text { rod surface temperature for segment } \mathrm{i} \\
& \mathrm{Tc}_{0, \mathrm{i}}=\text { initial coolant temperature associated with segment } \mathrm{i} \\
& \mathrm{Ts}_{0, \mathrm{i}} \quad=\text { rod surface temperature for segment } \mathrm{i}
\end{aligned}
$$

Since heat generated in the rod is not instantly transferred to the fluid and since surface temperature is a non-linear function of heat transfer rate to the fluid, both the rod surface temperatures and the associated fluid temperatures will vary dynamically and may exhibit non-linear oscillations. Pressure drop oscillations may also result. The proposed experiment offers a way to study these reactivity feedback phenomena and generate data for code validation without the many difficulties of using an actual nuclear fuel rod. The coolant flow may be either single-phase or, with boiling induced, two-phase. A singlephase water flow experiment might be designed to represent either a PWR or a VHTR. A similar experiment would probably require sodium coolant to be representative of a fast reactor because of the high thermal conductivity of sodium and resultant axial heat conduction in the flow channel. Reactivity feedback effects in a BWR, such as void reactivity feedback (Lahey, Jr., and Moody, 1979), could be studied by inducing boiling.

The apparatus, shown in Figure 12, would consist of a stack of cylindrical heaters contained within a cylindrical flow channel. The apparatus would be placed in a flow loop capable of providing the required inlet flow conditions. The power delivered to each heater element would be individually controlled as a function of measured surface and fluid temperatures associated with the heater element according to the above equation. The heater power input would be controlled by a LabView computer program (National Instruments, Inc.) that incorporates the feedback equation. Further analysis would be necessary to specify geometry and dimensions, number of heaters, and ranges of operating parameters such as flow rate, power, pressure, and temperatures. 


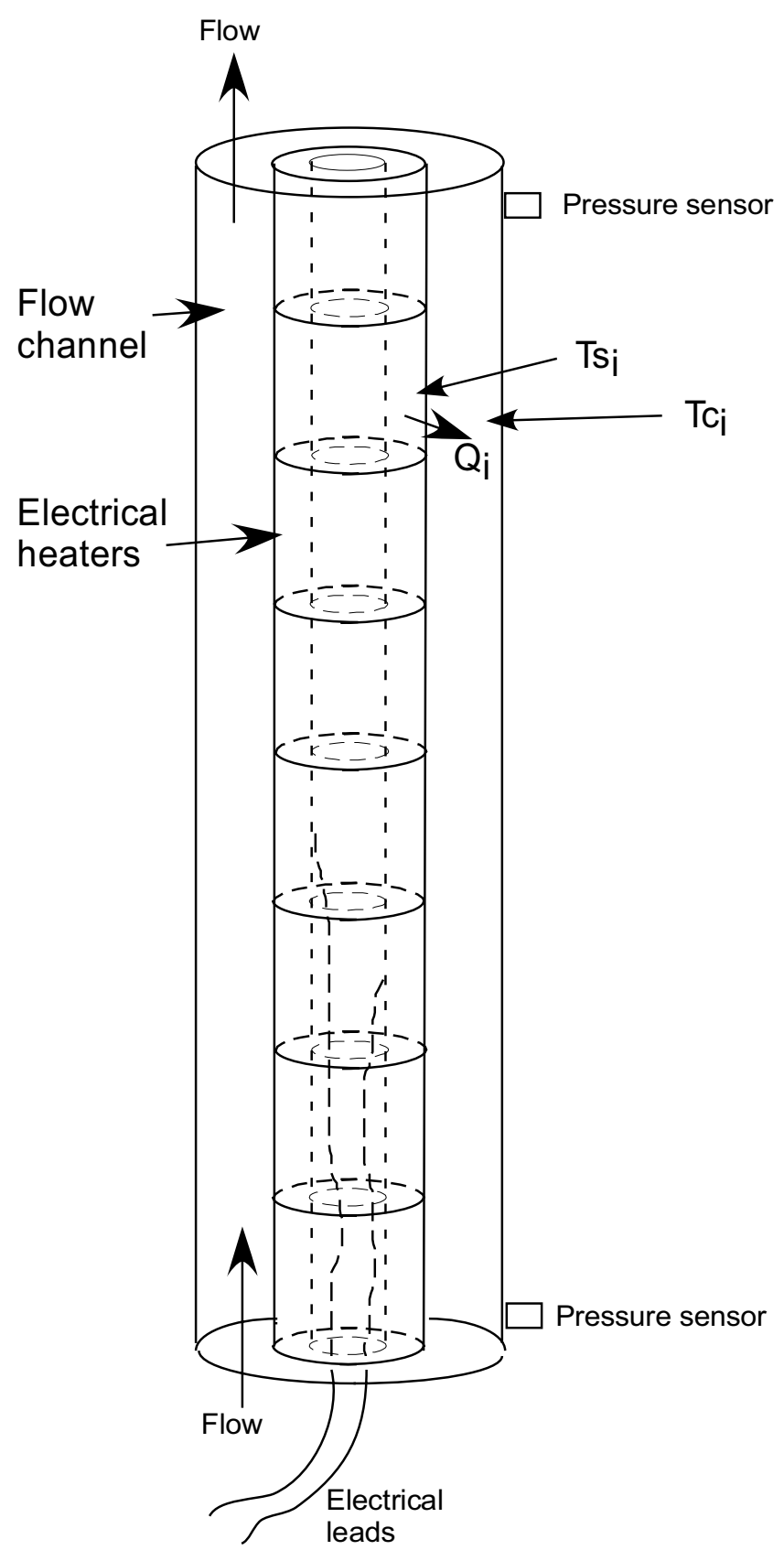

Figure 12. Electrically heated reactivity feedback experiment apparatus. 


\section{Appendix 1. Fast-Reactor Rod Bundle Matched-Index-of-Refraction Experiments}

Experiments are planned to be conducted in the INL Matched Index-of-Refraction (MIR) Flow Facility to characterize the three-dimensional velocity and turbulence fields in a wire-wrapped rod bundle typically employed in liquid-metal cooled fast reactors. The model will be constructed of quartz components and the working fluid will be mineral oil. The model will be a scaled 7-pin rod bundle enclosed in a hexagonal duct made of fused quartz. Flow field measurements will be obtained with a 3-D particle image velocimeter (PIV) and possibly complimented with near-wall and boundary layer measurements by a 2-D (and possibly a 3-D) laser Doppler velocimeter (LDV). The data from these measurements will be processed and analyzed. Data analysis and displays will include tables, charts, diagrams and pictures as necessary. The MIR facility, the PIV system, and a preliminary experiment design are described.

\section{A1.1. Matched-Index-of-Refraction (MIR) Facility}

Velocity field measurements will be obtained in the MIR Flow Facility closed-loop flow system located at the INL Engineering Demonstration Facility (Bldg IF 657) in Idaho Falls, Idaho (see Figure A1- 1). The system consists of a stainless steel closed flow loop with a three-chamber polycarbonate test section with glass windows. The facility operates with light mineral oil as the working fluid.

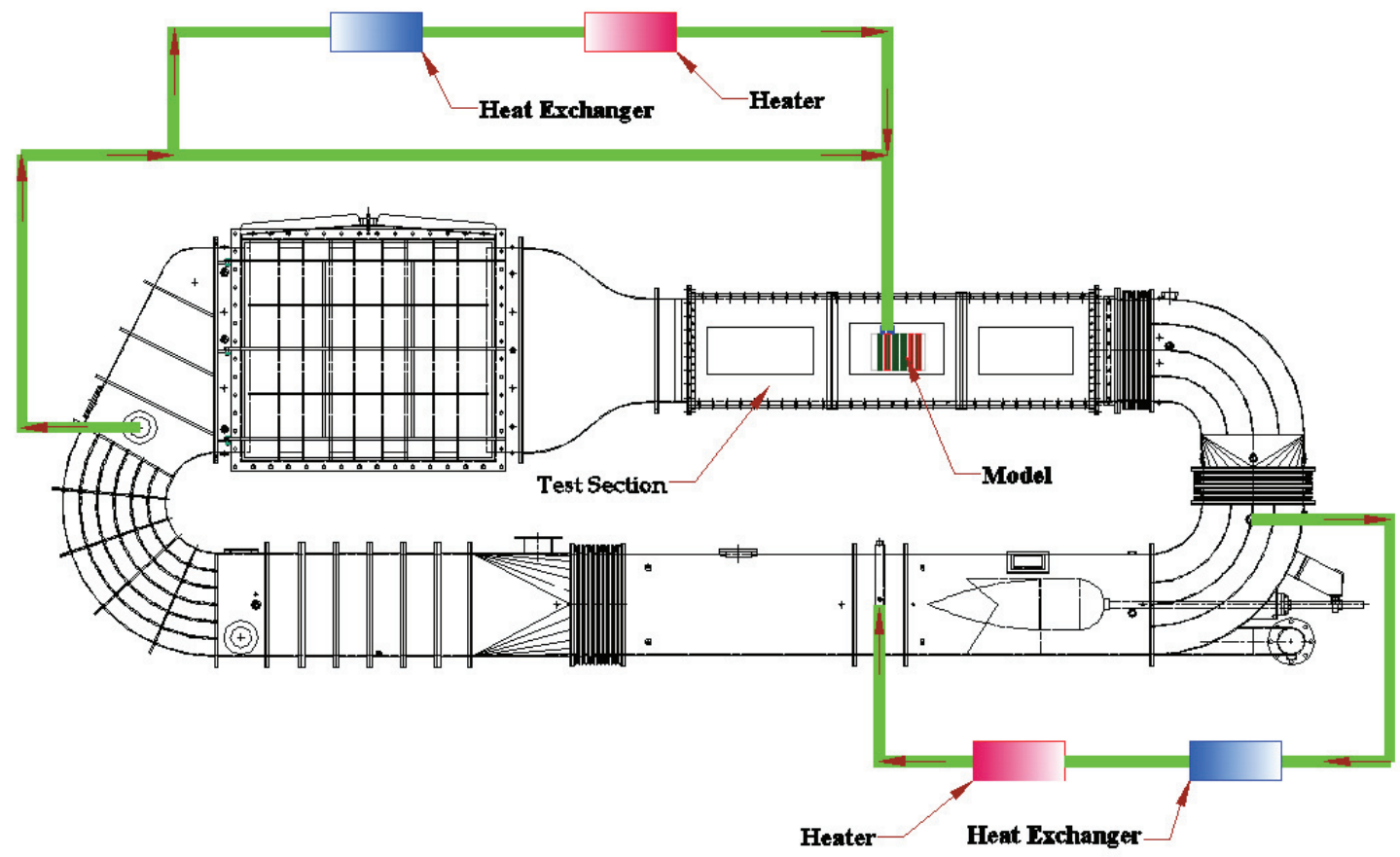

Figure A1-1. MIR Facility Closed Loop Flow System. 
The mineral oil working fluid is circulated around the loop (clockwise in Figure A1-1) by a 75-hp variable speed axial pump that can provide a maximum volumetric flow rate of approximately $0.6 \mathrm{~m}^{3} / \mathrm{sec}$. This maximum volumetric flow rate corresponds to a maximum inlet velocity to the test section of approximately $1.7 \mathrm{~m} / \mathrm{sec}$. The test section includes three chambers that are constructed of $3.8 \mathrm{~cm}$ thick polycarbonate supported by a stainless steel framework. Each chamber is fitted with a removable lid. The test section inside dimension is $0.61 \mathrm{~m}$ square and it is $2.44 \mathrm{~m}$ long. Each chamber of the test section is equipped with glass window inserts in the side panels to accommodate high quality measurements with laser Doppler velocimetry (LDV) and/or particle image velocimetry (PIV). The entire facility can be supported on pneumatic vibration isolators.

The working fluid temperature is maintained with a temperature control loop as shown in the lower right corner of Figure A1-1. This loop extracts approximately $300 \mathrm{l} / \mathrm{min}$ of mineral oil from the primary flow loop and pumps the fluid through a glycol-cooled heat exchanger and a $10 \mathrm{~kW}$ DC heater for temperature control. The fluid is then filtered and re-injected into the primary flow loop. The temperature control system can maintain the fluid temperature in the test section to within $\pm 0.05{ }^{0} \mathrm{C}$ of the specified index-matching temperature $(23.4 \mathrm{C})$. An auxiliary flow loop shown in the upper left corner of Figure A1-1, with a similar temperature control mechanism, is used to provide fluid for models/experiments that require additional flow. As shown in Figure A1-1, fluid is extracted from the primary flow loop and routed to a seven horsepower auxiliary pump that can produce high-pressure, high speed flow to the test section as required. To maintain the required fluid temperature, a portion of this fluid is extracted from the auxiliary flow loop and routed through a parallel auxiliary temperature control loop. As in the primary temperature control loop, the mineral oil is cooled and reheated and then returned to the auxiliary flow loop. Instrumentation to control the system is centralized at an Operator's Station.

\section{A1.2. Particle Image Velocimetry (PIV) System}

Velocity field measurements will be obtained with a 3-D PIV from LaVision, Inc. The 3D PIV system consists of two ImagePro Plus digital CCD cameras and a double-pulsed Nd-YAG laser. The system is controlled with DaVis 7.1 software in a LaVision dualprocessor Programmable Timing Unit (PTU). The PIV system cameras are mounted on a 3-dimensional traverse system that is controlled by three separate electric stepping motors. The cameras can be positioned and re-positioned to with 2 micron accuracy using linear stages and digital readouts at the Operator's Station. The laser is also controlled with an electric stepping motor. The laser can be positioned and re-positioned to within 5 micron accuracy with an optical linear stage and digital readout that is also located at the operator's station. A two-component, TSI fiberoptic-based laser Doppler velocimeter is also available for velocity field measurements. 
Figure A1-2 is a picture of the 3-D PIV system that is presently installed on the MIR Facility. The two CCD cameras shown in the figure can be mounted in various configurations designed to support specific model geometries. Additionally, the doublepulsed laser shown beneath the test section in the figure can also be mounted to support specific experimental requirements.

Figures A1-3 and A1-4 are samples of the type of data and displays that can be obtained with the PIV system. Figure A1-3 is a plot of the vector field obtained from a combination of six vector fields collected along the centerline of a model of the lower plenum of a typical prismatic gas-cooled reactor. The vector colors represent average velocities. Figure A1-4 is a plot of streamlines obtained from the data. The PIV data can be easily exported to other software systems (such as TecPlot and VisIt) to obtain various other data displays that are suitable for comparisons with code calculations.

Figure A1-3 shows a center-plane slice of the 3-D velocity field for the entire VHTR lower plenum model. Streamlines are shown in Figure A1-4. Four inlet jets are operating at a Reynolds number of 12,400 - the maximum attainable flow in the plenum model. The dark areas between the vector fields and streamlines are the support posts which are located along the centerline of the model, as shown in the drawing of the apparatus in Figure A1-5. The vector field and streamline representation clearly describe the inlet jet flow as it enters the lower plenum in the upper right of the picture and the resulting interaction of the inlet flow and support posts along the centerline of the model. The two figures also describe a recirculation area/vortex in the lower right corner of the picture. This recirculation is formed at the reflector wall near the bottom of the plenum, and is the result of nearly vertical flow from the inlet jets encountering the bottom surface of the plenum and the reflector wall. A portion of this nearly vertical flow turns downstream and begins its transit toward the plenum exit but some of the flow turns toward the reflector wall and flows upward along the reflector wall surface. 


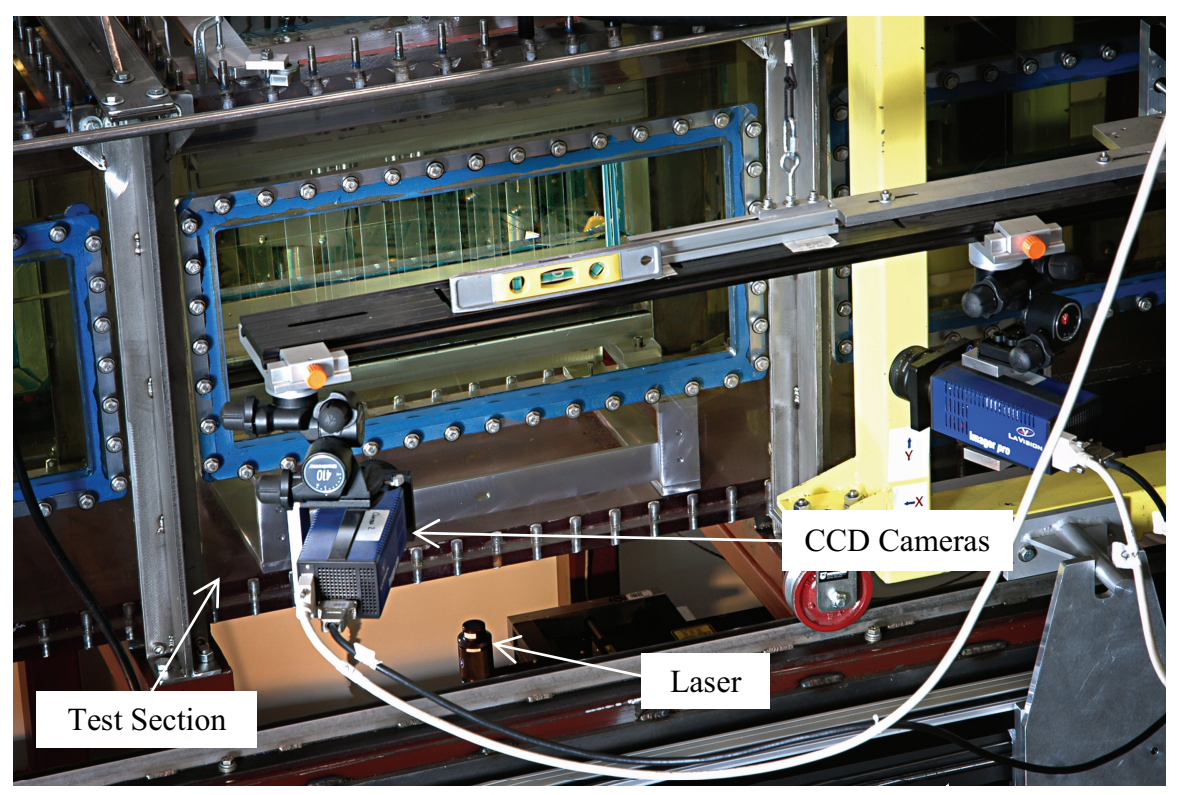

Figure A1-2. 3-D PIV System Installed on MIR Facility Closed Loop Flow System.

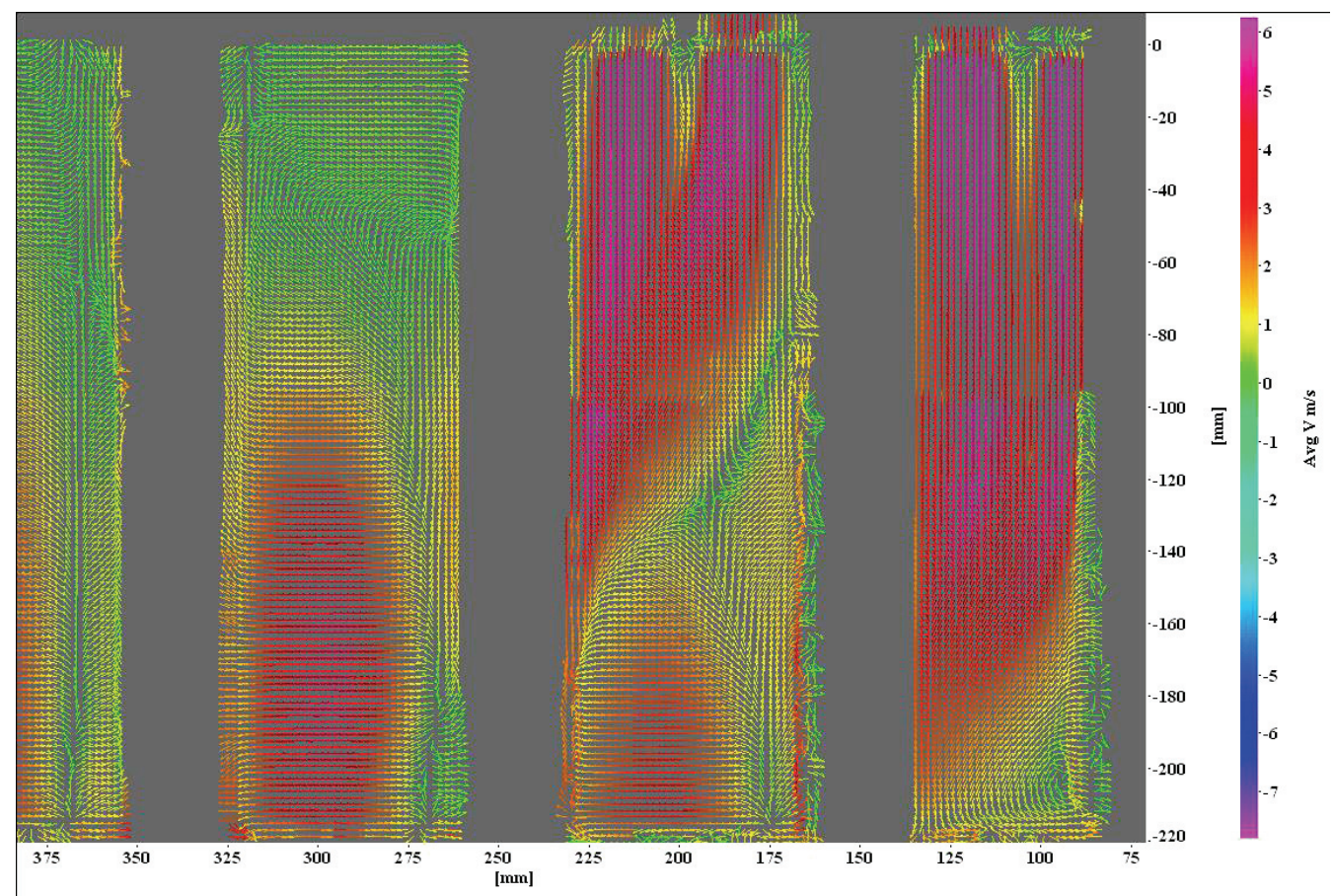

Figure A1-3. Mid-plane velocity vector field. 


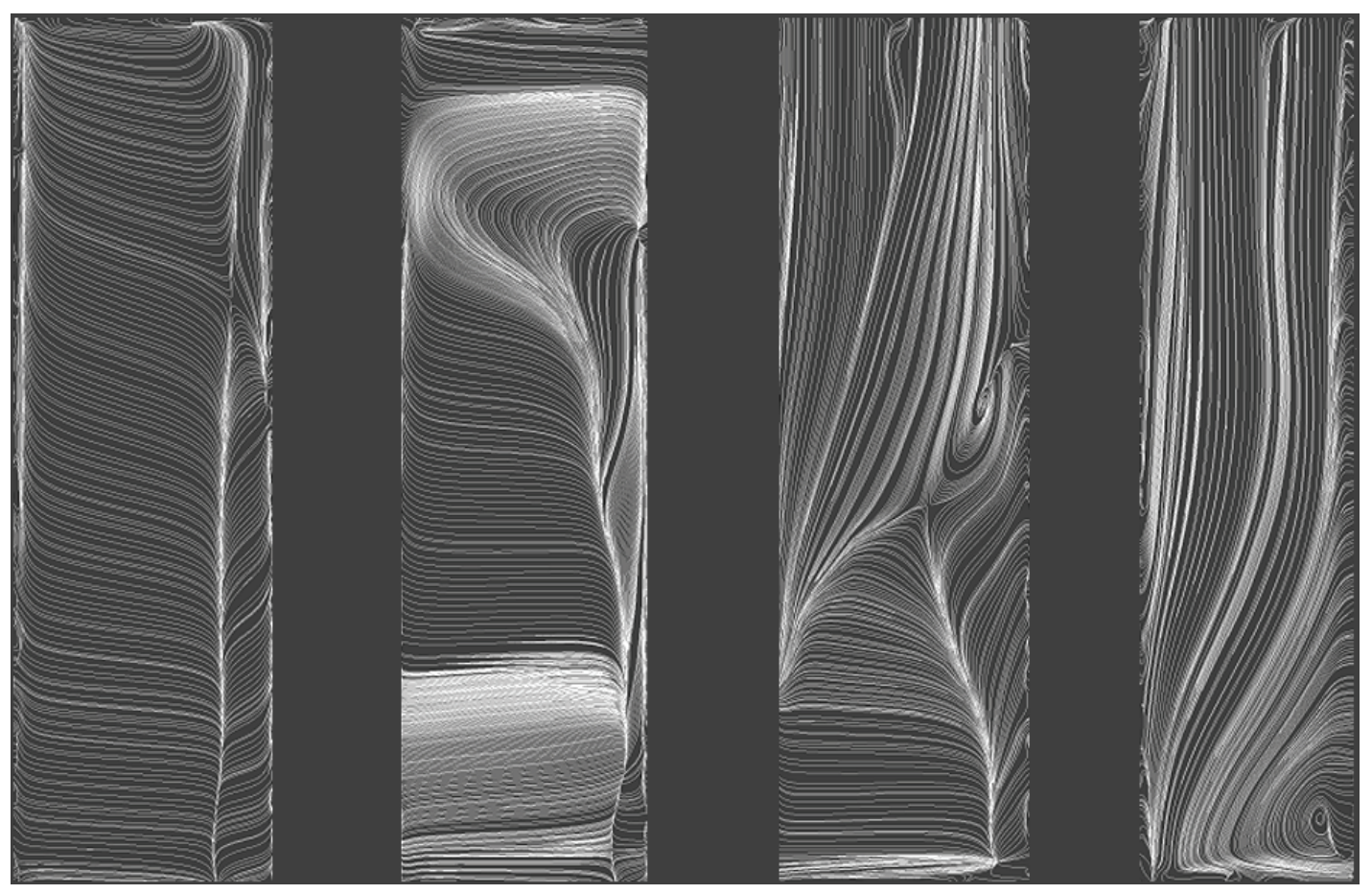

Figure A1-4. 3-D PIV Steamline Plot. 


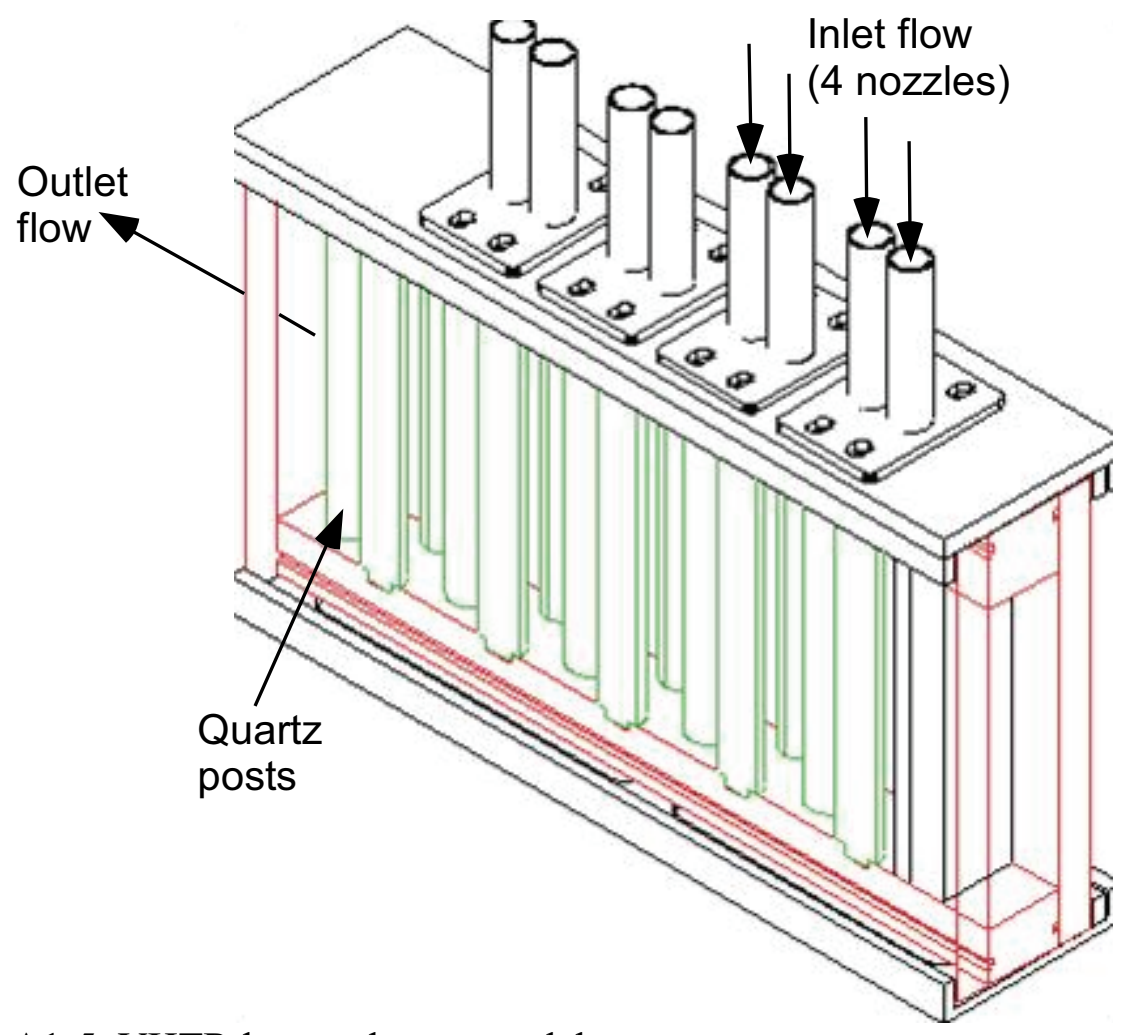

Figure A1-5. VHTR lower plenum model. 


\section{A1.3. Preliminary Matched-Index-of-Refraction Rod Bundle Experiment Design.}

A preliminary design of an experiment to be conducted in the INL Matched Index-ofRefraction (MIR) Flow Facility is described in this section and a cost estimate for apparatus construction is given. The objective of the experiment is to characterize the three-dimensional velocity and turbulence fields in a wire-wrapped rod bundle typically employed in liquid-metal cooled fast reactors. The design focuses on a seven rod bundle since a three rod bundle was not thought to provide sufficient subchannel cross-flow and mixing (obtaining cross-flow data was stated by CFD personnel to be a primary objective for these experiments). Also, calculations show that flow in a 19 rod bundle model, the next larger triangular pitch symmetrical bundle that fits in a hexagonal duct, would not provide sufficiently high Reynolds numbers for fully turbulent flow.

The design relies on a Mathcad computer program that was developed to calculate flow, pressure loss, pumping power, and temperature increase in physical models placed in the MIR loop test section with flow provided by either the main loop flow or the auxiliary loop. The program provided sufficiently accurate calculation for the design of the one previous rod-bundle experiment that was conducted in the MIR flow loop (McEligot, et al., 2003) and for other model configurations such as the lower plenum model discussed above. The previous rod bundle experiment was a two-rod bundle with spacers and enclosed in a rectangular cross-section duct which was representative of a supercritical water reactor core design. Pressure losses for the rod bundle are calculated using the Novendstern (1972) correlation, which formulates overall bundle loss coefficient as a function of Reynolds number, rod pitch, and wire wrap pitch.

Two design approaches were investigated. The first approach is to position the rod bundle in the test section and funnel main-loop flow through the bundle. The second approach is to use the auxiliary flow and temperature control loop to provide flow to the bundle, which would also be positioned in the main loop test section and surrounded by oil circulating in the main loop (necessary to eliminate non-orthogonal window distortion and for temperature control purposes). The two approaches are shown schematically in Figures A1-6 and A1-7. Both design approaches have been used in previous experiments and have their individual advantages and disadvantages. The maximum main-loop flow is higher than the maximum auxiliary loop flow, but the maximum pump delivery head is lower. Thus an experiment designed for main loop flow should have higher flow but lower flow resistance than one designed for the auxiliary loop. The top lids on the main loop test section must be secured for experiments designed for main loop flow and the air must be carefully purged from the loop or air bubbles will cloud the camera views. Experiments which use the auxiliary loop may be run with free-surface flow in the main loop and with the top lids open, which is preferable for access to pressure taps, for repositioning the model, etc. Because of these design restrictions, the optimum size of a model bundle will be larger for a main loop flow experiment than an 
auxiliary loop flow experiment. The optimum size of the model is one that provides the maximum possible Reynolds numbers while also providing sufficient length/hydraulic diameter and length/wire-wrap pitch to insure well developed flow, where model length is limited to slightly longer than the test section length of eight feet. It is assumed in the present design that maximum Reynolds number is the most important criterion.

Cheng and Todreas, 1984, generated correlations for flow transitions in wire-wrapped rod bundles using their own and other's data. Figure A1-2 from their article, reproduced below in figure A1-8, illustrates the Reynolds number transitions. The laminar to turbulent flow transition occurs over a much larger range of Reynolds numbers in comparison to internal tube flow due to the variations in internal dimensions. Turbulence is reported to first occur in the subchannel region midway between three surrounding rods in a triangular pitch array and to then slowly propagate with increasing Reynolds number to the narrower regions between adjacent rods. 

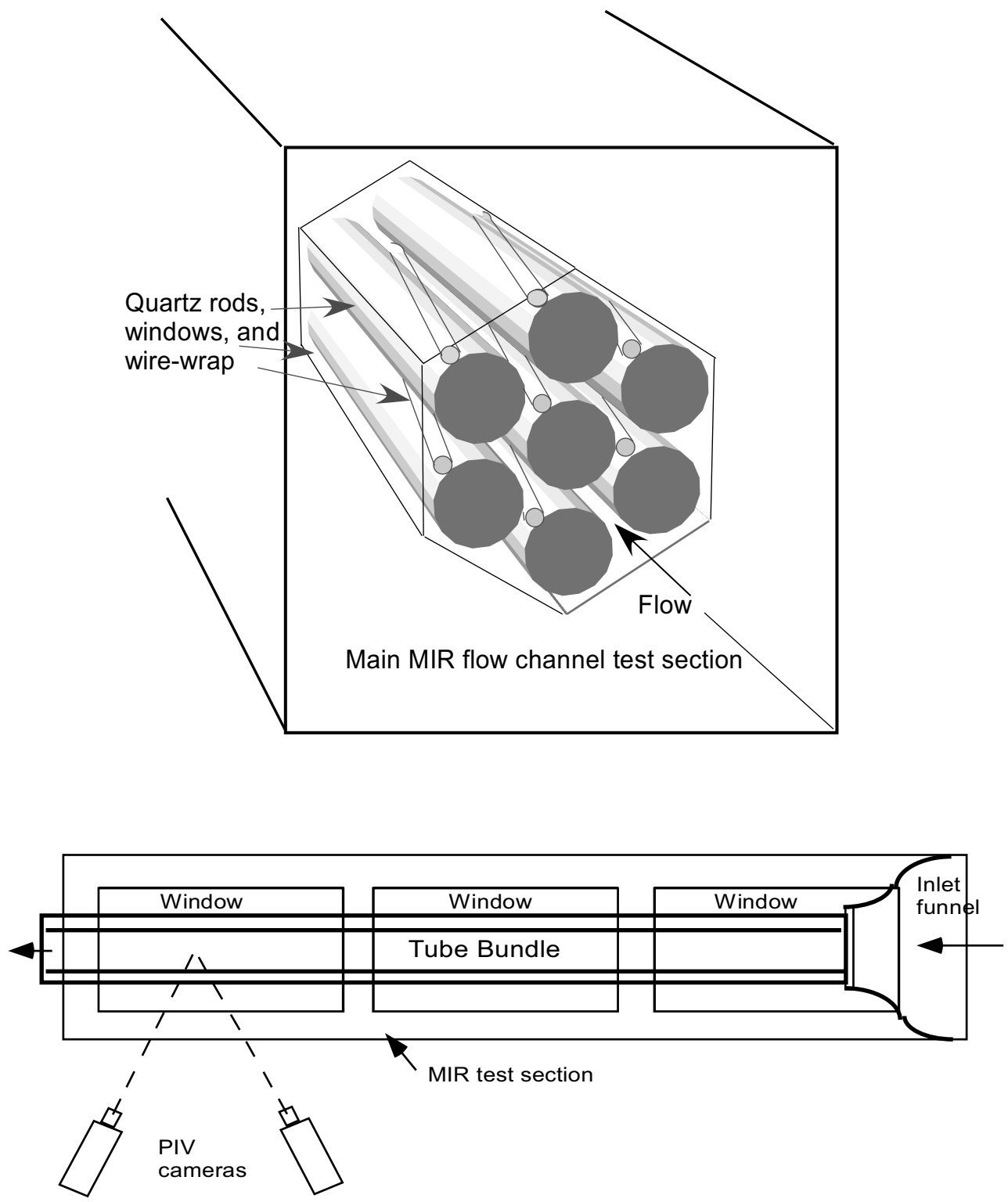

Side View

Figure A1-6. 7-rod bundle positioned in main MIR flow loop test section. Main MIR flow funneled through bundle. 


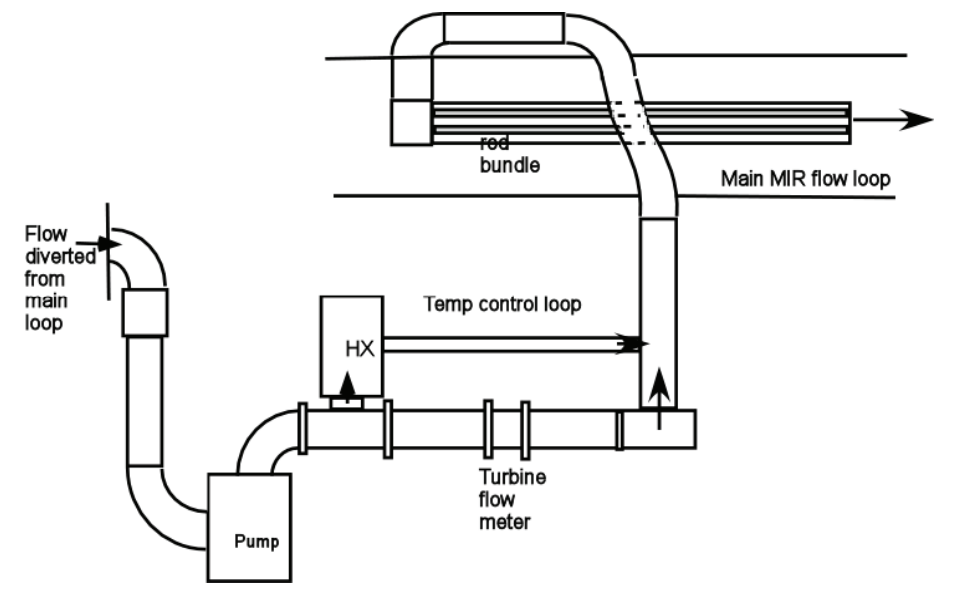

Figure A1-7. Schematic of 7-rod bundle positioned in the main MIR flow loop test section with flow provided by auxiliary loop. 


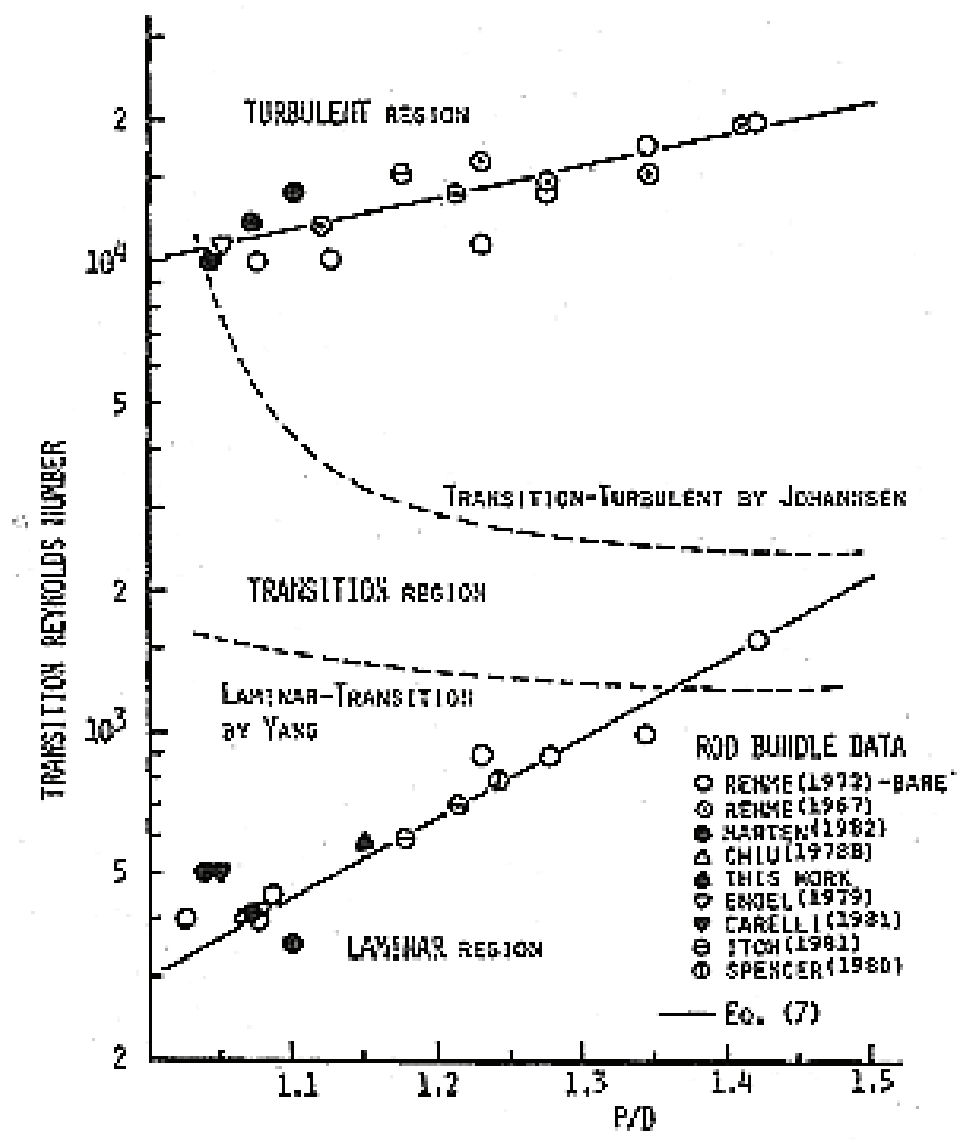

Fi3. 2. Dith and proposed oortations for the iransilles Rezrolds number.

Figure A1-8 . Reynolds number transition map for flow in wire-wrapped rod bundle. From Cheng and Todreas, 1984. 


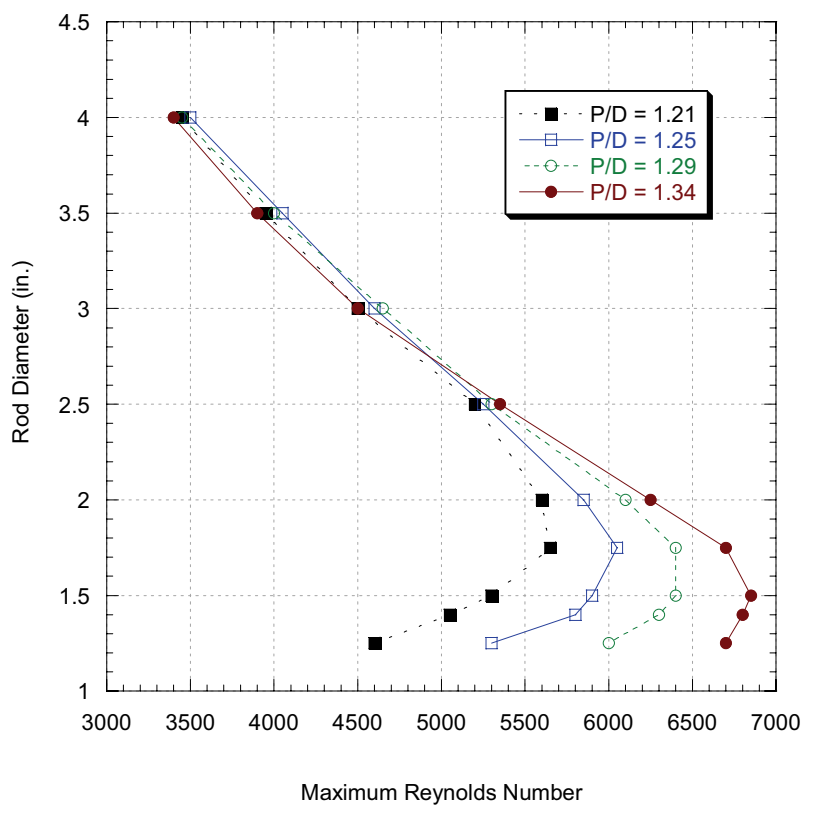

Figure A1-9. Calculated maximum Reynolds number achievable in a 7-rod bundle with flow provided by the auxiliary MIR loop as a function of rod diameter and pitch/diameter ratio. 


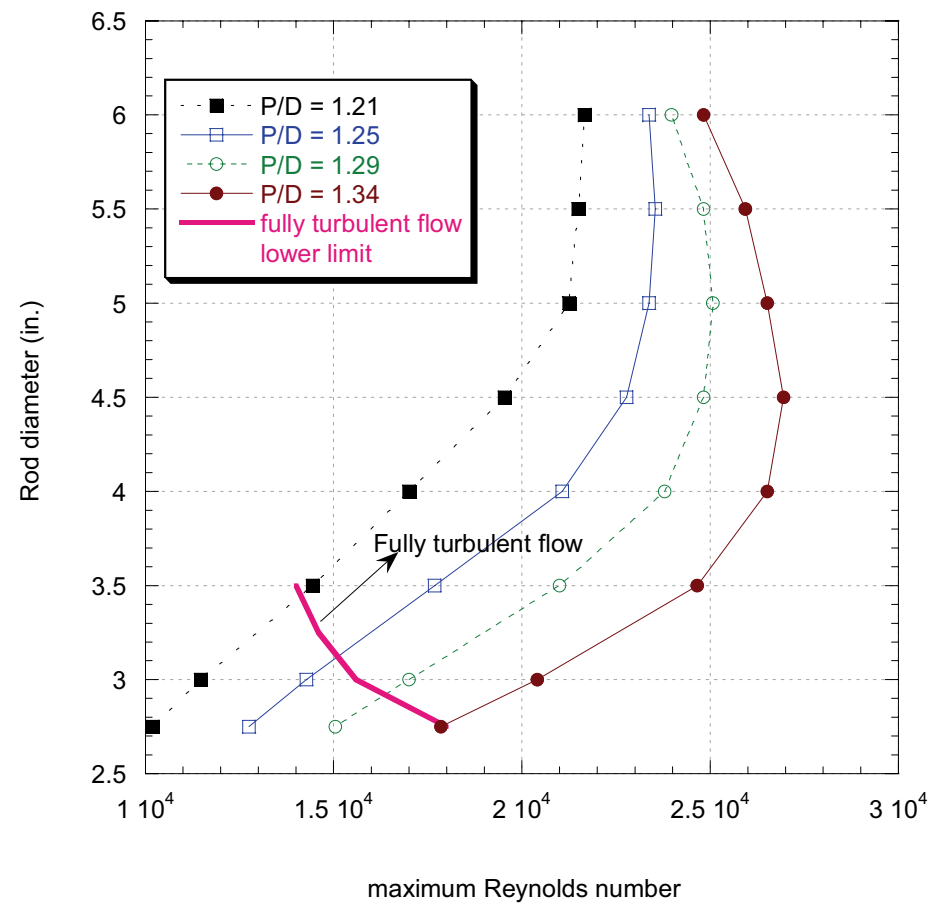

Figure A1-10. Calculated maximum Reynolds number achievable in a 7-rod bundle placed in the main MIR test section as a function of rod diameter and pitch/diameter ratio. 
It is clear from an examination of figures A1-10 and A1-11 that an experiment using a model designed for main loop flow will provide a significantly higher Reynolds number than one designed for auxiliary loop flow unless the pumping capacity of the auxiliary loop were to be increased by at least a factor of three. An increase of pumping capacity of this magnitude would require a complete redesign of the loop rather than merely the purchase of a new pump. Although increasing the capacity of the auxiliary loop would be a valuable improvement for the MIR facility, it is probably prudent to design the present experiment to use main loop flow.

A preliminary choice of bundle design that insures sufficiently high Reynolds numbers for fully turbulent flow while maintaining a reasonable length/hydraulic diameter ratio and uses commercially available quartz tubes (the fuel rods will be simulated using quartz tubes rather than quartz rods since rods of this large a diameter and sufficient length are not commonly available) and rods (the wire-wrap will be simulated by quartz rods) is given in Table A1.

\section{Table A1. Rod bundle nominal design dimensions}

$\begin{array}{ll}\text { Rod Diameter } & =85 \mathrm{~mm}(3.346 \text { in.) } \\ \text { Rod Pitch/Diameter } & =1.294 \\ \text { Wire wrap diameter } & =25 \mathrm{~mm}(0.984 \text { in.) } \\ \text { Wire wrap Pitch/Rod Diameter } & =14.34 \\ \begin{array}{l}\text { Length/Hydraulic Diameter } \\ \begin{array}{l}\text { Number of wire wraps } \\ \text { (on } 8 \mathrm{ft} . \text { length rod) }\end{array}\end{array} & =38.76\end{array}$

The maximum achievable Reynolds number in this design is approximately 24,000, which exceeds by a comfortable margin the minimum Reynolds number for fully turbulent flow of approximately 18,000, according to the Cheng and Todreas, 1984, correlation which is displayed in Figure A1-8. (Calculations for a 19 rod bundle that fits within the confines of the flow loop give a maximum Reynolds number of approximately 12,000 , which is not sufficiently high for fully turbulent flow). The choices of rod pitch/diameter and wire wrap pitch/diameter are chosen to fall within the range of prototypical values listed in Tang, et al., 1978, although they do not correspond to one particular prototype. Other choices of bundle design parameters are, of course, possible and are open for discussion. The final choice must use commercially available quartz 
tubes and rods and will be a compromise between maximum achievable Reynolds number, rod pitch/diameter, bundle length/hydraulic diameter, and number of wire wraps. The choice must also be compatible with PIV camera and MIR test section windows placement (most reasonable bundle model designs should meet the requirement).

The design of the physical model shown in Figure A1-12 uses commercially available quartz tubes for the simulated fuel rods, quartz rods for the simulated wire wrap, and quartz and glass plates to construct the simulated canister. The rod bundle is designed to rotate on-axis in order to permit views from various angles for the PIV cameras. The simulated fuel rods and canister will be approximately $8 \mathrm{ft}$. in length; the length of the MIR test section. However, quartz tubes are only available in lengths of six feet or less, quartz rods in lengths of four feet or less, and quartz plates in lengths of two feet or less (for our required width). Therefore, the quartz section of the channel will be used for the bundle section viewed by the approximately two foot length downstream window of the MIR test section (placed furthest downstream of the bundle entrance to help insure fullydeveloped flow) and the remainder of the channel will be constructed from glass plates. The eight foot length quartz tubes and 9.8 foot length of rods (the length required to wrap the eight foot tube length) will be constructed from two or more tubes or rods spliced together and flame polished. The procedure described by National Scientific Co., who quoted the quartz component prices, is to butt weld the quartz tubes and rods together while mounted on a lathe to maintain alignment and then to grind and polish the joints. This procedure will require careful machining, joining and polishing of the components in order to maintain smooth fluid flow near the walls. The simulated wire wrap will be constructed by heating a quartz rod to its softening temperature and then wrapping it around a simulated fuel rod and then pinning it in place at the ends to prevent movement. The dimensions and tolerances for the quartz components are stated in Table A2. The tolerance buildup of constructing the rod bundle from individual wire-wrapped rods may require manufacture of the individual wire wrapped rods first and then, after measuring the over-all dimensions of the bundle, constructing the simulated canister and supporting structure to fit. Careful recordings of as-built dimensions are required for code validation purposes. A cost estimate for construction of the apparatus is given in Table A3.

Table A2. Rod bundle quartz component dimensions and tolerances.

$\begin{array}{ll}\text { Rod diameter } & =85 \mathrm{~mm}+/-1.5 \mathrm{~mm}(3.346 \text { in. }+/-0.06 \text { in.) } \\ \text { Wire wrap diameter } & =25 \mathrm{~mm}+/-0.5 \mathrm{~mm}(0.984 \text { in. }+/-0.02 \text { in.) } \\ \text { (Rod pitch/diameter } & =1.294+/-0.025)\end{array}$



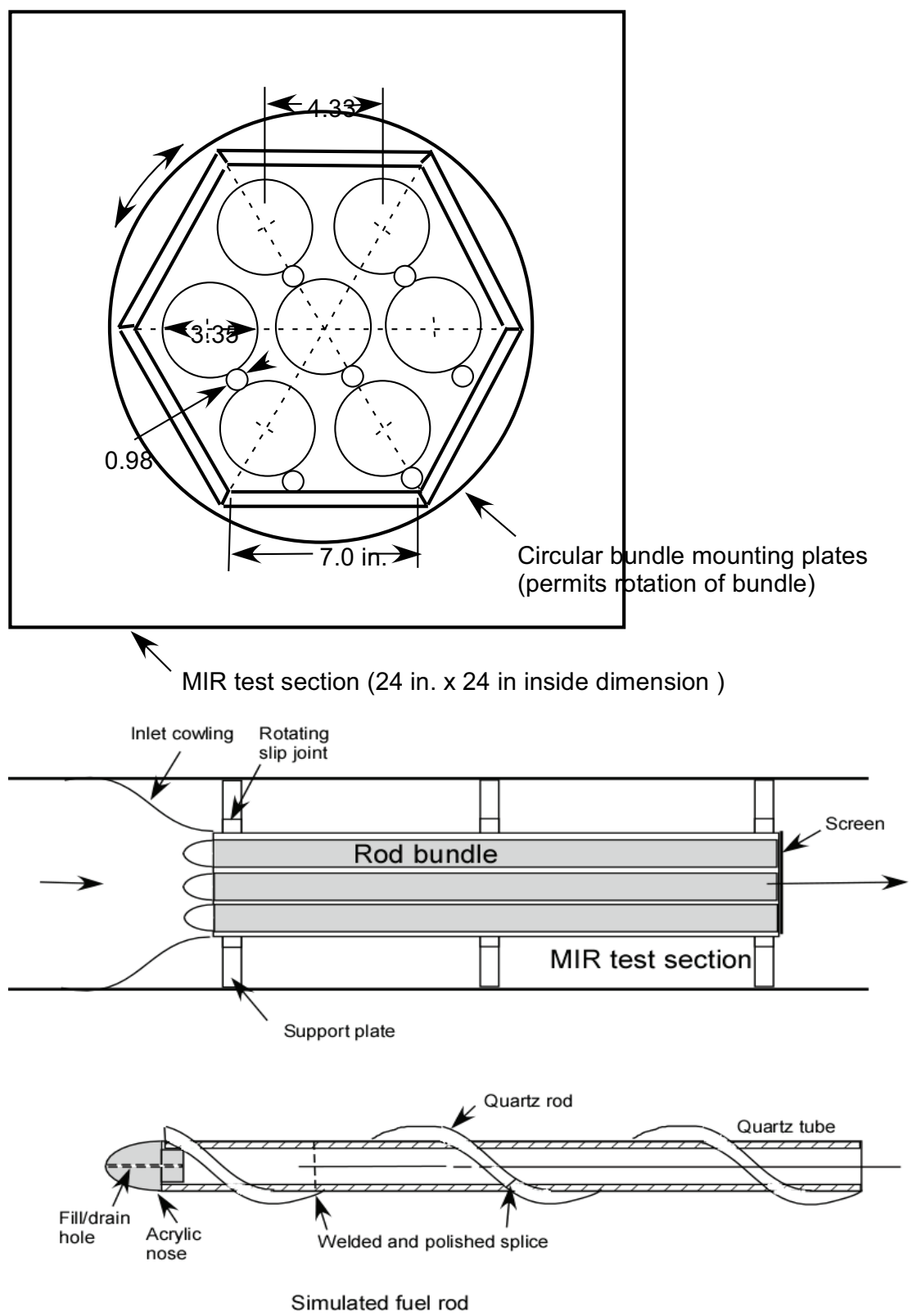

Figure A1-11. Bundle cross-section and details as located in MIR test section. Dimensions are in inches. (The screen shown in the figure is to prevent rod movement) 
Table A3. Cost estimate for apparatus construction

Design and mechanical drawings

24

Quartz components (National Scientific Co., Quakertown, PA)

11

Non-quartz materials

Component fabrication (Pacific Quartz, Santa Anna, CA)

20

Support structure machining

5

Mineral oil

9

Total

$\$ 74 \mathrm{~K}$ 


\section{Appendix 2. Sodium cooled rod bundle facility preliminary cost estimate.}

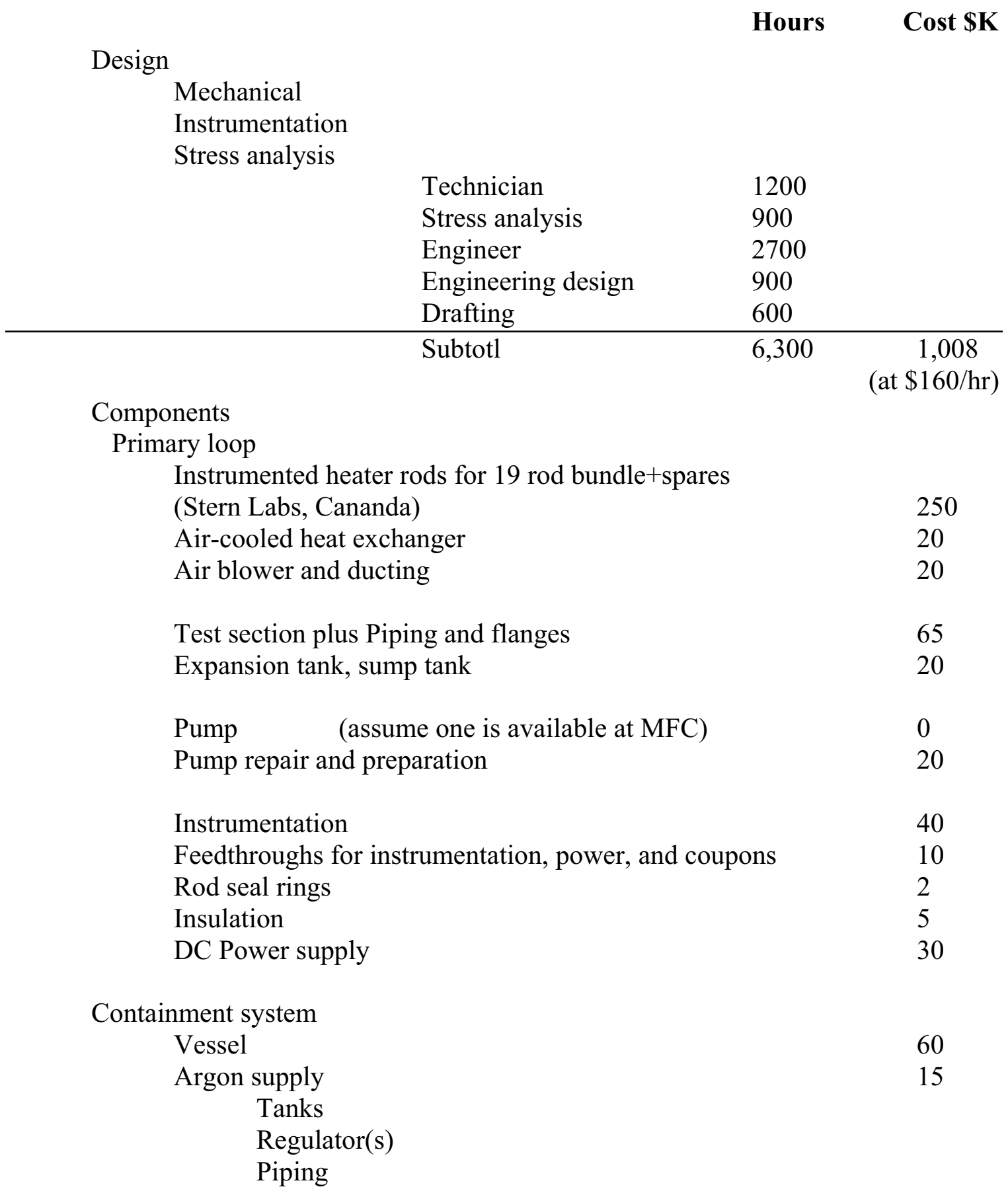


$\begin{array}{ll}\text { Fire suppression system } & 30\end{array}$

$\begin{array}{ll}\text { Sodium fill system } & 50\end{array}$

sodium 20

$\begin{array}{ll}\text { sodium chemistry system } & 20\end{array}$

$\begin{array}{ll}\text { Piping } & 10\end{array}$

$\begin{array}{ll}\text { Structure } & 20\end{array}$

Platform

Portable crane

$\begin{array}{ll}\text { DAS/control (included in instrumentation) } & 15\end{array}$

Labview software

$\begin{array}{ll}\text { Control room } & 20\end{array}$

Racks

Displays

Partitions

Cable trays

$\begin{array}{ll}\text { Electrical switch gear } & 10\end{array}$

Flow loop construction $\quad 40$

Facility modification and preparation $\quad 500$

(assumes cost share with NASA EM pump project, total cost $=\$ 1 \mathrm{M}$ )

IHR

Total

Plus $15 \%$ contingency 


\section{Appendix 3. Laboratory Candidate Buildings}

Possible buildings for locating thermal hydraulic laboratories are described in this section. The buildings are located in-town and at MFC and other site locations. Descriptions of the individual facilities discussed below may be obtained from the INL Facilities Planning Data Base,

http://fmprod.inel.gov

\section{A3.1. In-town facilities}

The two connecting bays of the West wing of IEDF (IF 657) have been used recently for the diesel reforming project funded by the U.S. Navy. This project is now terminated. The building has significant advantages as a thermal hydraulics laboratory. The building is tall (63 ft), has an overhead crane, has sufficient floor space (approximately 4,000 ft2 for both bays or 2,000 $\mathrm{ft} 2$ for one), is across the hall-way from the MIR laboratory, and across the street from IRC and BCTC. This would be an ideal location to set up a steamair-water two phase flow loop and large and tall separate effects experiments as well as smaller thermal hydraulics experiments. However, present power availability is not sufficient for an integral electrically-heated PWR facility (1-2 MW is required). Also, the Navy "gave" the INL the diesel reformer equipment without the funding to remove it, so the burden will probably be on the new tenant.

Contact: Doug Hilde 


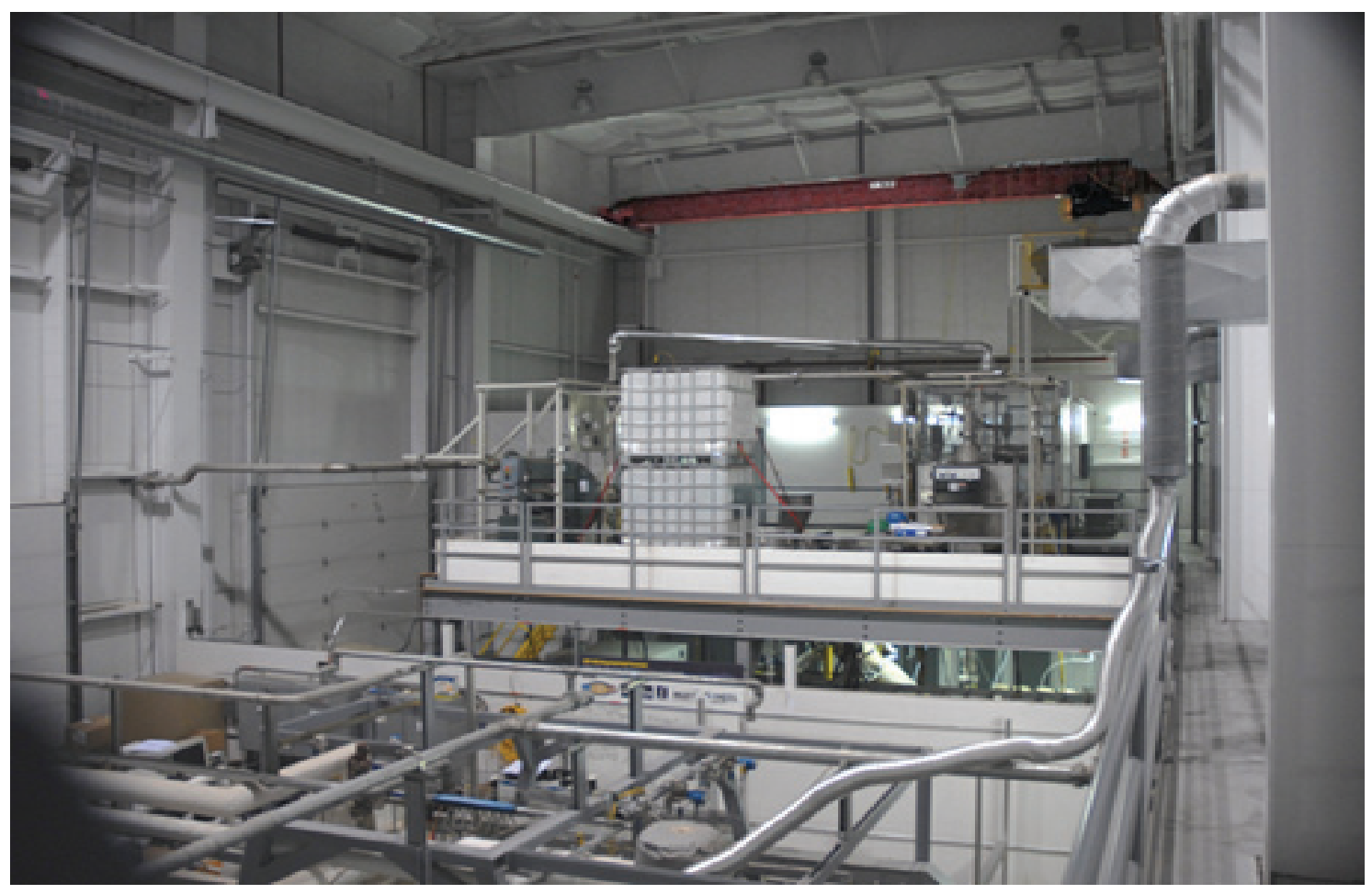

Figure 4. West wing of IEDF showing two roll-up doors, overhead crane, and equipment left over from diesel reformer project. 


\section{A3.2. MFC Facilities Suitable For Sodium Handling}

Although there is extensive experience in sodium handling at MFC, primarily related to EBR-II reactor operation and clean-up, there is no laboratory, in the sense of a room or building dedicated to performing experimental work using sodium, currently available. Existing facilities listed below have the equipment and infrastructure for sodium handling.

The limit of sodium that may be stored and used in experiments in a normal laboratory setting is $10 \mathrm{lb}$ according to the international building code (IBC). While sodium is a flammable solid, the 10 pound limit is actually based on its being a water reactive (class three) chemical per IBC. Since $10 \mathrm{lb}$ is only approximately 1.5 gallons of liquid sodium, a normal laboratory setting is insufficient for handling a suitable quantity of sodium to carry out reasonably scaled forced or natural convection thermal hydraulics experiments where the sodium volume might be from several to several hundred gallons.

To go over 10 pounds in a facility, the facility has to meet the requirements of a hazardous $(\mathrm{H})$ facility. There are different types of $\mathrm{H}$ facilities: ones for flammables, toxics, corrosives etc. In order to handle the large inventory of chemicals that we have in the chemical storage building some of the rooms are built to $\mathrm{H}$ requirements like the flam storage room and the room that highly toxics are stored. Jane Welch was not aware of any existing lab building that meets this requirement so it is likely that an $\mathrm{H}$ facility would have to be built or something added to retrofit an existing building. These types of buildings/rooms have more requirements to meet but they do exist and the requirements are not overwhelming. The same requirements would apply to site or town. Features of an $\mathrm{H}$ building for sodium handling include, for example, using an inert cover gas to prevent sodium reactions, special fire-extinguishing capabilities, and pits to contain any spilled sodium. It would probably be preferable to convert one of the (non-laboratory) buildings at MFC that is dedicated to sodium handling to a laboratory than to build a new $\mathrm{H}$ facility. The most probably choice is the Sodium Boiler Building MFC 766 since this has been identified by Dan Wachs as the location for the NASA sponsored flow loop for liquid metal EM pump flow testing. It would be advantageous to the INL to develop the flow loop with sufficient capacity for both the pump testing and GNEP rod bundle heat transfer and natural circulation testing. Separate pool natural circulation experiments could also be performed in the same laboratory.

MFC-799 Sodium Processing Facility $7329 \mathrm{ft} 2$ Process elemental sodium to sodium hydroxide Proposed transformation project footprint reduction building list for FY11 May possibly be used in the future for FFTF sodium waste processing 
The building is classified as a RCRA site and is subject to RCRA rules and regulations. The building would need to be delisted as a RCRA site before the building could be used for research activities without imposing onerous regulations and paperwork.

Contact: Paul Henslee

Engineering development laboratory

MFC 772 and $789 \quad 5199$ and $2390 \mathrm{ft} 2$ floor space

MFC 772 is currently dedicated to the space battery program and MFC 789 to fuel pyroprocessing. The NaK flow loop, mentioned in the "Path Forward" section is located in this facility.

Contacts: Scott McBride, Ken Bateman, Greg Teske

EBRII Power Plant

MFC $768 \quad 43,100 \mathrm{ft} 2$

The EBRII Power Plant is a large high-bay facility with sufficient height, floor space, an overhead crane, and sufficient power for conducting experiments using sodium as well as for housing an integral electrically-heated full-height PWR facility.

Sodium component maintenance shop (SCMS)

MFC $793 \quad 4382 \mathrm{ft} 2$

Contact: Scott McBride

Fuels and applied science building (FASB)

This is a nuclear programs owned facility. It is used for Preirradiation inspection, assembly, and testing of radioactive materials.

MFC $787 \quad 6023 \mathrm{ft} 2$

Contact: Tom O'Holleran

MFC 766 Sodium Boiler Building

$14,547 \mathrm{ft} 2$

Status: operational standby

This is the building identified by Dan Wachs for NASA sponsored testing of an EM pump using a sodium flow loop. 


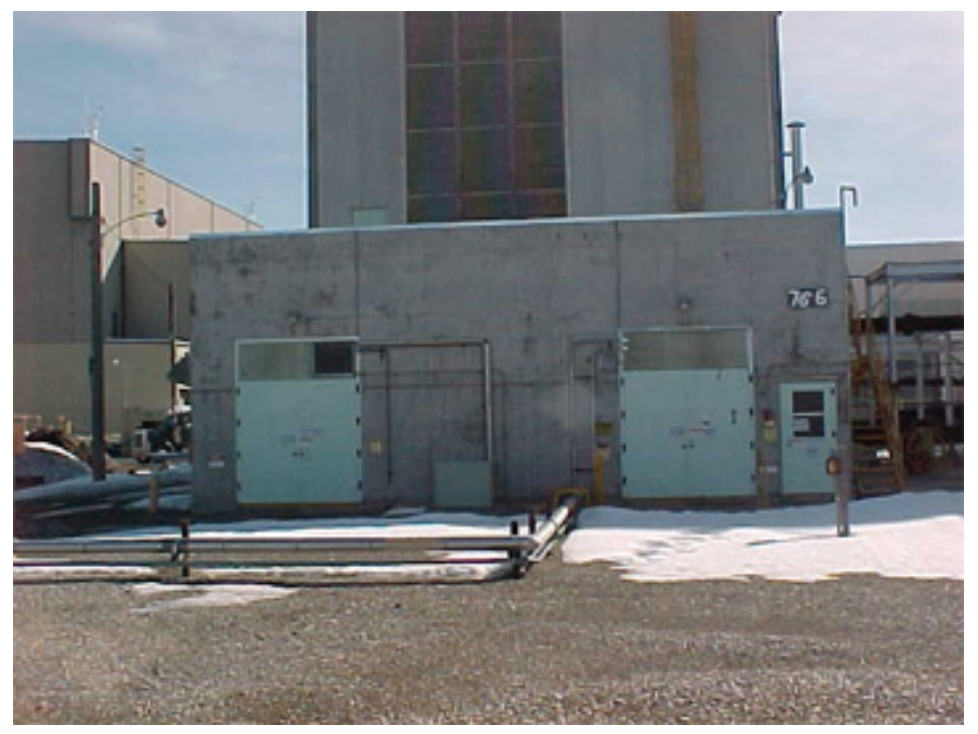

Figure 5. Sodium boiler building MFC 766.

\section{A3.3. Possible Integral Reactor Simulation Facilities}

A facility capable of housing a full-height full-pressure electrically-heated scaled PWR must have sufficient height (20 m minimum), sufficient power (1-2 MW), an overhead crane, and sufficient floor space. The prime candidate is the EBRII Power Plant (MFC 768), which is described above.

A list of tall buildings at INTEC that might meet the needs for a test loop in presented in Table A3-1 below. According to Barry O'Brien there is enough power at INTEC to support the 1-2 MW requirement as the total plant use was $>4 \mathrm{MW}$ and has been declining so there should be excess capacity. The switchgear between the coal fired plant and FPR can support up to $15 \mathrm{MW}$. The buildings are owned by CWI. 
Table A3-1. INTEC candidate buildings for an integral electrically-heated facility.

\begin{tabular}{|c|c|c|c|}
\hline Building & Name & Floor space & Status \\
\hline CPP688 & $\begin{array}{l}\text { Coal Plant } \\
\text { Unload Bldg }\end{array}$ & $4,166 \mathrm{ft}^{2}$ & $\begin{array}{l}\text { Shutdown pending } \\
\text { disposal }\end{array}$ \\
\hline СРP 687 & $\begin{array}{l}\text { Coal-Fired Boiler } \\
\text { House }\end{array}$ & $27,282 \mathrm{ft}^{2}$ & $\begin{array}{l}\text { Shutdown pending } \\
\text { disposal }\end{array}$ \\
\hline СРP691 & $\begin{array}{l}\text { Fuel Processing } \\
\text { Restor. Fac. } \\
\text { (FPR) }\end{array}$ & $160,611 \mathrm{ft}^{2}$ & Operating \\
\hline СРP691 & $\begin{array}{l}\text { Remote Insp. Engr } \\
\text {. Facility }\end{array}$ & $160,611 \mathrm{ft}^{2}$ & $\begin{array}{l}\text { Operating pending } \\
\text { D\&D }\end{array}$ \\
\hline
\end{tabular}




\section{Appendix 4. Scaling approaches for light-water electrically-heated integral facilities}

Following the conclusion of the Semiscale program (Loomis, 1987) a USNRC commissioned study was conducted at the INL to define scaling concepts upon which future integral thermal hydraulic experimental facilities should be based (Condie, et al., 1987). Four separate scaling concepts were evaluated based on their ability to reproduce important PWR reactor thermal hydraulic phenomena. Five important transient classes were identified which include (1) increase in heat removal, (2) decrease in heat removal, (3) anticipated transient without scram, (4) small-break loss-of-coolant accident (LOCA), and (5) large-break loss-of-coolant accident. It was concluded that a facility capable of operating at typical reactor operating conditions will scale most phenomena well. Although many phenomena in facilities using Freon or water at non-typical pressure will scale reasonably well, those phenomena that are heavily dependent on steam quality, such as heat transfer or critical flow, will not be faithfully reproduced. The full-height fullpressure scaling concept, such as employed in Semiscale and more recently in the ROSAIV facility in Japan, which simulated a Westinghouse AP600 reactor ( Yonomoto, et al, 20001), provides the most faithful reproduction in the five identified transient classes as well as steady-state flow forced and natural convection. The RELAP5/MOD3 code was assessed (the word "validated" was not used) by INL staff by analyzing small-break LOCA and transient experiments conducted in the ROSA-IV facility (Schultz, et al, 1997).

The ROSA-IV Large Scale Test Facility (LSTF) is a 1/48 volumetrically scaled, fullheight, full-pressure simulator of a Westinghouse-type 4-loop (3423 MWt) PWR. LSTF was used to conduct integral experiments on PWR small break loss-of-coolant accident and operational transients as part of the Rig-of-Safety-Assessment No. 4 (ROSA-IV). The hot and cold legs were sized to conserve the volume scaling. The four primary loops of the reference PWR are represented by two equal-volume loops.

If a facility is designed to represent a specific portion of a complete blowdown or other transient then alternate scaling concepts may be employed that simplify the facility design, reduce cost, and in some cases reproduce local phenomena more faithfully. For example, the APEX facility located at Oregon State University was designed to primarily investigate low pressure long term cooling in Westinghouse AP600 and AP1000 reactors and is a one-quarter linear scale reduced pressure one-half time scaled integral system (Reyes and Hochreiter, 1998). Another example is the PUMA facility located at Purdue University (Ransom et al., 1998) which is a full-pressure, $1 / 4$ height scale, one-half time scaled representation of a General Electric Simplified Boiling Water Reactor (SBWR). The PUMA facility is based on the scaling methods developed by Ishii and others for natural circulation loops (Ishii and Kocamustafaogullari, 1961, and Ishii and Jones, 1976). The facility was designed to simulate the low-pressure $(<150 \mathrm{psi})$ behavior of a 
SBWR. Initial conditions must be obtained from either scaled SBWR conditions or from code calculations. Initial conditions include the pressures, temperatures, mass inventories, noncondensible gas fraction, flow rates, etc., which are obtained from RELAP5 code calculations. Other SBWR scale facilities include GE's GIST facility and the GIRAFFE facility in Japan, which are both full-height, full-pressure facilities 


\section{References:}

Barber, T. T., "Role of Code Validation and certification in the Design Environment," AIAA Journal, vol. 36, no. 5, p. 752, 1998.

Celik, I. B., 1999, "Introduction to Turbulence Modeling - A Short Course," West Virginia University, Mech and Aerospace Engineering Dept., presented at the INL Feb 2006.

Condie, K.G., Larson, T.K., Davis, C.B., and McCreery, G.E., "Evaluation of integral continuing experimental capability (CEC) concepts for light water reactor research-PWR scaling concepts", NUREG/CR-4824, EGG-2494, Feb. 1987.

Durst, F., Moffat, R.J., and Viskanta, R., "Advisory committee report on INEL long term research initiative (LTRI) in experimental thermal sciences", EG\&G internal report, September, 1992.

Eckert, S., Gerbeth, G., and Melnikov, V.I., "Velocity measurements at high temperatures by ultrasound Doppler velocimetry using an acoustic wave guide", Exp. In Fluids 35, 2003, pp. 381-388.

Gnadt, P.A., et al., "Sodium boiling experiments in the THORS facility", Nuclear Eng. Design, 82, 1984, pp. 241-280.+

Heisler, M.P., and Singer, R.M., "Facility requirements for natural convection shutdown heat removal", in Agarawal, A.K., and Guppy, J.G., "Decay heat removal and natural convection heat transfer in fast breeder reactors", Hemisphere, 1981, pp. 113-127.

Idaho National Laboratory Strategic Plan FY 2007-2016 "Leading the Renaissance in Nuclear Energy," INL/EXT-06-11807, 2007.

Ishii, M., and Kocamustafaogullari, G., "Scaling criteria for two-phase flow natural and forced convection loop and their application to conceptual 2x4 simulation loop design", NUREG/CR-3420, ANL-82-61, 1961.

Ishii, M., and Jones, O.C., Jr., "Derivation and application of scaling criteria for twophase flow, two-phase flows and heat transfer", Proc., vol.1, NATO Advanced Study Institute, Istanbul, pp. 163-183.

Ishitori, et al., "Experimental study of sodium natural convection heat transfer in the intermediate plenum for pool-type LMFBRs", Nuc. Eng. And Design, 90, 1987, pp. 431440. 
Lahey, Jr., R.T. and Moody, E.J., "The thermal-hydraulics of a boiling water nuclear reactor", American Nuclear Society, 1979.

Lee, et al., "Investigation of fundamental thermal-hydraulic phenomena in advanced gascooled reactors”, INL/EXT-06-11801, MIT-GFR-033, September, 2006.

Loomis, G.G., "Summary of the Semiscale Program (1965-1986)", NUREG/CR-4945, EGG-2509, July, 1987.

Marvin, J. G., "Perspective on Computational Fluid Dynamics Validation," AIAA Journal, vol. 33, no. 10, p. 1778, 1995.

MacDonald, P. E., J. W. Sterbentz, R. L. Sant, P. D. Bayless, R. R. Schultz, H. D. Gougar, R. L. Moore, A. M. Ougouag and W. K. Terrry, "NGNP preliminary Point Design -- Results of the initial neutronics and thermal-hydraulic assessments", INEEL/EXT-03-00870 Rev. 1, 2003.

McCreery, G.E., Condie, K.G., and Schultz, R.R., "Scaled Experimental modeling of VHTR Plenum Flows", ICONE-15 conference, Nagoya, Japan, April 2007.

McCreery, G.E., and Condie, K.G., "Experimental Modeling of VHTR Plenum Flows during Normal Operation and Pressurized Conduction Cooldown", INL/EXT-06-11760 28 September 2006.

McCreery, G.E., Larson, T.K., and Condie, K.G., "Once Through Steam Generator AFW Flow Distribution and Heat Transfer”, Hassan, Y.A., editor, Thermal Hydraulics of Nuclear Steam Generators/Heat Exchangers, ASME HTD, 102, 7-20, 1989.

McEligot, D.M., and McCreery, G.E., "Initial Scaling Studies and Conceptual Thermal Fluids Experiments for the Prismatic NGNP Point Design", INEEL/EXT-04-02367, Sept. 2004

McEligot, D.M., et al., "Advanced computational thermal fluid physics (CTFP) and its assessment for light water reactors and supercritical reactors", INEEL/EXT-03-01215, December, 2003.

McEligot, D. M., et al., "Fundamental thermal fluid physics of high temperature flows in advanced reactor systems, Final. Report”. INEEL/EXT-2002-1613, INEEL, 2002.

Nalezny, C.L., "summary of Nuclear Regulatory Commission's LOFT Program Experiments”, NUREG/CR-3214, EGG-2248, July, 1983.

"NGNP Research and Development Plan" (no authors listed), INEEL/EXT-05-02581, January, 2005. 
Novendstern, E.H., "Turbulent flow pressure drop model for fuel rod assemblies utilizing a helical wire wrap spacer system”, Nuc. Eng. Design, vol. 22, 1972, pp. 19-27.

Ransom, V.H., Wang, W., and Ishii, M., "Use of an ideal scaled model for scaling evaluation", Nuclear Engineering and Design 186, 1998, pp. 135-148.

Reyes, J.N., and Hochreiter, L., "Scaling analysis for the OSU AP600 test facility (APEX)", Nuc. Engr. And Design, 186, 1998, pp. 53-109.

Reyes, J.N., Groome, B.W., Jackson, B., and Marshall, T.D., "Scaling analysis for the high temperature gas reactor test section (GRTS)", paper 166, NURETH-12, Pittsburgh, Sept. 30-Oct. 4, 2007.

Richter, B., et al., "Report of Advanced Nuclear Transformation Technology Subcommittee of the Nuclear Energy Research Advisory Committee", October, 2006. http://www.ne.doe.gov/nerac/neracPDFs/anttReport2006Final10-07-06.pdf

Ricou, R. and Vives, C., "Local velocity and mass transfer measurement in molten metals using an incorporated magnet probe", Int. J. Heat Mass Transfer, vol. 25, 1982, pp. 15791588.

Roach, P. J., "Verification and validation in Computational Science and Engineering", Chap. 9, Hermosa Publishing, Albuquerque, NM,1998.

Rosen, M.C. and Ribando, R.J., "A numerical study of flow in the thermal-hydraulic outof-reactor safety facility expansion tank”, Nuc. Eng. And Design, 68, 1981, pp. 373-383.

Schultz, R.R., Hanson, B., Kullberg, C.M., Liou, C.P., McCreery, G.E., Newman, N., and Westacott, J., "RELAP5/MOD3 Code Assessment Analyses based on the ROSA-AP600 Program: Small Break LOCA's and the Station Blackout Transient, March, 1997.

Stacey, S.M., "Proving the principle, a history of the Idaho national engineering and environmental laboratory 1949-1999”, DOE/ID-10799, 2000.

Tang, Y.S., Coffield, Jr., R.D., and Markley, R.A., "Thermal analysis of liquid metal fast breeder reactors", American Nuclear Society, 1978.

Tokuhiro, Akira, "Experimental Development and Demonstration of Ultrasonic Measurement Diagnostics for Sodium Fast Reactor Themohydraulics", NERI project 07037, Program Area AFC R\&D, 2007.

Von Weissenfluh, T., "Probes for local velocity and temperature measurements in liquid metal flow", Int. J. Heat Mass Transfer, vol 28, no. 8, 1985, pp. 1563-1574. 
Wolf, J.R., "Investigation of heat transfer in supercritical fluids for application to the Generation IV supercritical water-cooled reactor (SCWR)", project number 2004-002-K, INERI 2006 Annual Report, DOE/NE-0131, June, 2007.

Yonomoto, T, et al., "Summary Report ROSA-AP600 Program”, JAERI-memo-13-009, March, 2001. 